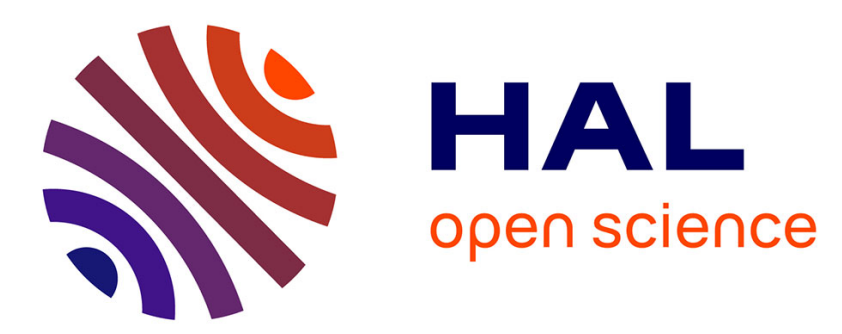

\title{
The effect of ambient temperature shocks during conception and early pregnancy on later life outcomes
}

Joshua Wilde, Bénédicte Apouey, Toni Jung

\section{To cite this version:}

Joshua Wilde, Bénédicte Apouey, Toni Jung. The effect of ambient temperature shocks during conception and early pregnancy on later life outcomes. European Economic Review, 2017, 97, pp.87-107. 10.1016/j.euroecorev.2017.05.003 . halshs-01579660

\section{HAL Id: halshs-01579660 \\ https://shs.hal.science/halshs-01579660}

Submitted on 31 Aug 2017

HAL is a multi-disciplinary open access archive for the deposit and dissemination of scientific research documents, whether they are published or not. The documents may come from teaching and research institutions in France or abroad, or from public or private research centers.
L'archive ouverte pluridisciplinaire HAL, est destinée au dépôt et à la diffusion de documents scientifiques de niveau recherche, publiés ou non, émanant des établissements d'enseignement et de recherche français ou étrangers, des laboratoires publics ou privés. 


\title{
THE EFFECT OF AMBIENT TEMPERATURE SHOCKS DURING CONCEPTION AND EARLY
}

\section{PREGNANCY ON LATER LIFE OUTCOMES}

\author{
Joshua Wilde* \\ Bénédicte H. Apouey ${ }^{\dagger}$ \\ Toni Jung
}

May 22, 2017

\begin{abstract}
A large body of research has recently shown that early life or in utero shocks, especially climatic shocks, may affect long-run human capital outcomes. Most of these effects are assumed to be biological - including poor nutrition during critical windows of fetal development, or through increased maternal stress. However, in addition to these biological effects, climatic conditions at the time of conception may also cause changes in parental behavior, not only affecting the mix of parents who conceive, but also the characteristics of the children once born. This paper explores whether increases in ambient temperature at the time of conception, while in utero, or after birth cause better educational and health outcomes as adults. Using Census and Demographic and Health Survey data from sub-Saharan Africa, we show that individuals conceived during high temperatures have higher educational attainment and literacy. In addition, we find evidence of temperature

\footnotetext{
${ }^{*}$ Corresponding author. Email: jkwilde@usf.edu. Mailing address: University of South Florida, 4202 East Fowler Avenue, CMC 342, Tampa, FL 33620, USA. Tel.: 813-974-2076. Fax: 813-974-6510.

†Email: benedicte.apouey@psemail.eu. Paris School of Economics - CNRS, 48 Boulevard Jourdan, 75014 Paris, France.

‡Email: toni.jung@att.com. AT\&T, 1120 20th St. NW., Washington DC., 20036, USA. Research was completed before author began employment at AT\&T.
} 
effects at other times in utero, especially during the first trimester. We then explore the biological and behavioral mechanisms through which this effect may occur, including heat-induced changes in sexual behavior, differences in parental characteristics, and intensified fetal selection. We conclude that fetal selection is the most likely mechanism driving our result. We also show that temperature deviations change the mix of conceiving women to be wealthier, partly since heat-induced reductions in sexual activity are larger for poorer women.

JEL Codes: I12, I15, J13, O15.

Keywords: Temperature, Conception, Fetal Origins, Fertility, Human Capital. 


\section{Introduction}

Human capital is a fundamental component of labor productivity and income. For this reason, over the past several decades scholars and policy makers alike have emphasized the importance of education and health in reducing poverty in the developing world. A large number of studies explore the potential for early life environmental or nutritional shocks, especially in early childhood or in utero, to affect health, cognitive ability, educational attainment and other human capital outcomes. ${ }^{1}$ While this literature has well established the link between early life shocks and infant or child outcomes, a large but relatively smaller body of work looks at the long-run effects of these shocks. For example, Barker et al. (1990) famously argued that adverse nutritional shocks in utero affect the metabolic characteristics of the fetus which may lead to health problems later in life. But in practice, testing this hypothesis is difficult due to a range of competing factors, such as differential investment in less healthy children, fetal loss and natural selection, or behavior aimed at mitigating the effect of shocks. ${ }^{2}$

Recently, a considerable amount of attention has been placed on quantifying the effect of climate shocks on human capital outcomes given the interest in determining the "damage function" of climate change (Dell et al. 2014). This question is especially relevant given that most models of climate change not only predict an increased likelihood of extreme weather events, but also a disproportionate effect on the developing world the area least able to mitigate the adverse effects of these shocks. Several studies have explored the effects of weather variables - such as rainfall, temperature, windstorms, and snowstorms - on a large number of dependent variables, including health outcomes. But most of these studies focus on the contemporaneous effects of temperature on health, and not on its long-run effect. For example, there is a small but growing literature examining the effect of current temperature on mortality, cardiovascular conditions, or respiratory problems (Barreca 2012, Burgess et al. 2011, Curriero 2002, and Deschênes

\footnotetext{
${ }^{1}$ While this literature is much too voluminous to summarize here; see Almond and Currie (2011), Almond and Mazumder (2011), Bleakley (2007), Chen and Zhou (2007), Cutler et al. (2010), Deschênes et al. (2009), Gluckman et al. (2008), Maccini and Yang (2009), and Nikolov (2012) for recent examples.

${ }^{2}$ See Almond and Currie (2011) for an extensive discussion of these issues.
} 
and Greenstone 2011). Only two studies examine the effect of temperature shocks in utero on short-run health outcomes: Deschênes et al. (2009) who find that temperature spikes during the third trimester lower birth weight in the US, and Kudamatsu et al. (2012) who find that temperature in utero increases infant mortality in malarious and drought-prone areas of sub-Saharan Africa. And no studies link temperature in utero or after birth to any long-run human capital outcome. ${ }^{3}$

Another gap in the literature is the fact that the reduced form effect of temperature at the time of conception on long-run outcomes is likely to be very different than at other times in utero. For example, temperature changes may have heterogeneous effects on sexual behavior by socioeconomic status, affecting the mix of couples which select into pregnancy. Fetal loss also frequently occurs soon after conception. ${ }^{4}$ Therefore, the effect of natural selection may be more pronounced at this time than later in pregnancy when a negative shock may be more likely to scar the fetus than cull it. Finally, since women do not know they are pregnant at the time of conception, they may react differently to shocks compared with when the pregnancy is known. ${ }^{5}$ As a result, the reducedform effect of temperature on children conceived during temperature spikes is a mix of biological effects, behavioral effects from parents, and selection effects which are not present at other times in utero. To our knowledge, there are no studies investigating the link between temperature at conception and outcomes.

We fill these gaps by testing whether temperature spikes at conception, in utero, and immediately after birth causally affect long-run human capital outcomes. In particular, this paper estimates the monthly effect of temperature shocks from 6 months before conception to 3 months after birth on educational attainment, literacy, and disability as

\footnotetext{
${ }^{3}$ In fact, the only study to our knowledge which links any early-life climate variable with long-run outcomes is Maccini and Yang (2009) who find a positive effect of rainfall in the year of birth on selfreported adult health status, height, wealth, and educational attainment, but only for women. They find no effect for men.

${ }^{4}$ Boklage (1990) finds that 73 percent of natural single conceptions have no real chance of surviving 6 weeks of gestation, with most wastage occurring before detection. Wilcox et al. (1988) find that 22 percent of all pregnancies fail to implant, and Wilcox et al. (1999) find that of those which implant, 25 percent fail to survive an additional 2 weeks. 50 to 70 percent never become an established pregnancy while over 75 percent of conceptions do not lead to birth (Wilcox et al. 1988).

${ }^{5}$ Liu et al. (2014) note that over half of all conceptions terminate before the mother knows she is pregnant.
} 
adults in sub-Saharan Africa. We also test whether there is an effect on child mortality. Our methodology relies on using region-month of birth fixed effects to control for permanent geographic or seasonal characteristics which may affect these outcomes directly, allowing us to identify the effects using only the random variation in temperature. To do so, we merge gridded monthly weather data with the region, month, and year of birth of individuals found in Census records. Our Census data come from the six sub-Saharan African nations in the Integrated Public Use Microdata Series (IPUMS) International data repository for which detailed information on the timing of birth exists. These countries are Burkina Faso, Cameroon, Guinea, Malawi, Rwanda and Uganda. The gridded weather data are from Willmott and Matsuura (2012).

We find that larger temperature deviations around the time of conception and during early pregnancy are positively associated with better educational human capital outcomes later in life. For example, a one standard deviation shock in average monthly temperature nine months before birth increases years of schooling by 0.024 years, which corresponds to a 0.46 percent increase from the mean. Similarly, the probability of being literate increases by 0.37 percent. We find no statistically significant effect on disability status or infant mortality. In addition, we find that the effects of temperature 8 months before birth are 40-60 percent larger than the effects at conception, suggesting that the effects of temperature shocks are particularly important during very early pregnancy as well. We also sometimes find somewhat smaller effects in the third trimester as well. The effect of heat immediately after birth is similar to the magnitude and direction of the effect at conception for years of schooling and literacy, but again we do not find any effect of temperature shocks after birth for disability or infant mortality.

Given the reduced form nature of our results, it is important to keep in mind the limitations of our findings. If parents are engaged in compensatory investments in the human capital of the affected cohorts after birth, our results will be underestimated. In addition, temperature in utero may cause both scarring and culling of the fetus, leaving the overall effect the net of these two channels. Either way, our paper provides additional evidence and raises important questions for the literature on the fetal origins hypothesis. 
We then tease out the unique mix of biological, behavioral, and selection effects by testing a series of potential mechanisms which may be driving these correlations. These channels include differential coital frequency by socioeconomic status during temperature spikes, heat-induced parental selection into conception, and intensified in utero selection. Using birth record data from the Demographic and Health Surveys (DHS), the Malaria Indicator Surveys (MIS), and the AIDS Indicators Surveys (AIS) for 31 countries in subSaharan Africa, we show suggestive evidence that mothers in wealthier households are more likely to conceive during periods of elevated temperatures than poorer mothers. We also show that this selection may be driven by a reduction in the extensive margin of sexual activity, which falls more for poor women. We augment these findings by also showing reductions in the number of Google searches for sexually-themed keywords when temperature is higher than normal. But in spite of finding some evidence that parents who conceive children during temperature spikes may have better characteristics than those who do not, we show that there are no detectable differences between estimates of the effect of temperature at conception with or without controls for family wealth, suggesting that these differences in parental characteristics are not driving our results.

Selection on fetal quality in utero may also explain our findings, so we test this channel in three ways. First, we test whether known terminations at any point during the pregnancy are correlated with temperature at the time of conception, and find that, contrary to our expectations, temperature reduces the probability that a pregnancy ends in termination. Second, we find that temperature deviations at the time of conception affect the gender ratio, indicative of increased fetal loss. Finally, we find that the effect of temperature at conception on human capital outcomes is heterogeneous by gender. This also supports the fetal loss channel, since then the mean of the health distribution of surviving fetuses must be higher for males than for females if males are selected out at a higher rate via fetal loss. Taken together, our paper suggests that fetal loss is a likely driver of the correlation between above average temperature at conception and human capital outcomes later in life.

We also explore whether temperature deviations affect later life outcomes more if they 
occur during food-insecure times of the year - specifically during the rainy season which is both pivotal for agricultural production and the time of the year farthest from the last harvest and hence when food supplies are the most scarce. We find that temperature shocks during the rainy season - independent of before, after, or at the time of conception - affect later life outcomes of adults. This finding suggests that perhaps instead of temperature spikes being a health shock to the fetus directly, it may be the case that the effect is driven by food supplies and adverse nutritional shocks.

Finally, we show that temperature spikes have non-linear effects: deviations in temperature at conception and in utero have larger effects in regions where average monthly temperatures are higher than in cooler regions. This is a common result in the literature on temperature effects. Specifically, we find that the effect of a temperature spike in regions where the average temperature is greater than 24 degrees Celsius on years of education are 3.5 times greater than in regions with average temperatures less than 20 degrees. We also find similar effects for literacy rates, but not for disability rates.

Beyond our contributions to the literature on temperature and long-run outcomes, our new focus on temperature at the time of conception, and our finding that shocks during very early pregnancy may be especially important, our work also contributes to the literature on temperature and fertility rates. ${ }^{6}$ While this literature finds that birth rates fall nine months after a temperature spike, they do not identify the mechanisms driving this reduction. We show the first evidence that sexual activity falls with temperature, and also that temperature at the time of conception drives fetal loss. We also are the first study which uses Google search data to establish a link between high temperatures and reduced demand for online sexual services, strengthening our finding that sexual activity falls during temperature spikes. ${ }^{7}$

The paper proceeds as follows. Section 2 outlines our empirical methodology, and Section 3 presents our data. Section 4 presents our analysis on the correlation between temperature at conception and outcomes. Section 5 tests potential mechanisms by which

\footnotetext{
${ }^{6}$ Barreca et al. (2014); Lam and Miron (1991a, 1991b, 1994, 1996); Lam, Miron, and Riley, (1994); and Seiver $(1985,1989)$

${ }^{7}$ Markey and Markey (2013) find a correlation between searches and seasonality in the United States, but only suggest that temperature may be driving search behavior.
} 
temperature may affect outcomes later in life. Section 6 presents our analysis on nonlinear effects of temperature. Section 7 concludes.

\section{Methodology}

Estimating the effect of temperature at conception, in utero, and in early childhood on outcomes is not trivial. There are many reasons why absolute temperature should be correlated with outcomes even if no causal effect exists. For instance, temperature is clearly correlated with seasons. But month of birth has also consistently been shown to be an important predictor of a large range of later life educational, health, and labor market outcomes. ${ }^{8}$ Geographic characteristics may also be correlated with both weather and outcomes. For example, regions along coasts tend to have milder climates than landlocked regions, and coastal regions also have higher economic development due to lower transportation costs. In contrast, locations at higher elevations are colder and have lower levels of economic development. The presence of these confounding factors in the permanent component of temperature implies that a naive regression of outcomes on temperature will yield incorrect estimates.

In this paper, we remove the permanent component of temperature by including region-month fixed effects in our regressions, leaving only the random component of temperature to identify the temperature effect. This is more demanding of the data than simply using a measure of demeaned temperature, since the fixed effect will also control for everything else specific to that region-month besides temperature. Formally, we estimate the following regression equation:

$$
Y_{i, r, c, m, t}=\alpha_{c, t}+\theta_{r, m}+\sum_{j=t-15}^{t+3} \beta_{j} T_{j, i}+\psi X_{i, r, c, m, t}+\epsilon_{i, r, c, m, t},
$$

where $Y_{i}$ is the outcome of interest for individual $i$ at the time of the survey, $\alpha_{c, t}$ is a fixed effect for the country-year of birth, and $\theta_{r, m}$ is a fixed effect for the region-month of birth. In addition, there are up to 19 temperature variables $T_{j, i}$, corresponding to the average

\footnotetext{
${ }^{8}$ See Buckles and Hungerman (2013) Section III for a review of this literature.
} 
monthly temperature in the region of birth for each month from 15 months before the individual's birth to 3 months after birth. $X_{i}$ is a vector of other explanatory variables.

The main coefficient of interest is $\beta_{t-9}$. If $\beta_{t-9}$ is significantly different from zero, then elevated temperatures at conception are partially correlated with outcomes. However, we may be interested in the coefficients on other $\beta$ s as well. First, since not all conceptions occur precisely nine months before birth, we may expect that the coefficients on $\beta_{t-10}$ and $\beta_{t-8}$ will also pick up some of the effect of temperature at conception. Second, this specification not only allows us to look at the effect of temperature at the time of conception on outcomes, but also the effect of temperature before birth, in utero, and after birth.

\subsection{Concerns about Coefficient Bias}

One potential source of bias in our estimates is migration after conception but before birth. Since we only observe the location of birth, and not the location of conception, we cannot be exactly sure that the individuals in our sample were exposed to heat deviations in their region of birth. The direction of the resulting bias is unclear. However, given the rates of migration observed in the Census data, we believe that the fraction of children who were conceived in a location different from their birth is small. ${ }^{9}$

Another more difficult source of bias is the fact that gestation length is a random variable - some babies are premature, and as a result are actually conceived 8 months before birth or earlier, while other children are late and therefore may be conceived ten months before birth. As a result, it is difficult to determine whether t-9 is actually the correct month of conception. Assuming there is a conception effect, the higher the variance of gestation length, the lower the estimated coefficient on t-9 will be, and the more the conception effect will be picked up by the coefficients corresponding to the surrounding months.

Further complicating this issue is the well-documented phenomenon of gestation length actually being effected by adverse climatic conditions, including temperature. While there

\footnotetext{
${ }^{9}$ For example, only 6.87 percent of women of childbearing ages (15-44) moved within the last year in our sample.
} 
is no evidence to suggest temperature at the time of conception or early pregnancy affects gestation length, high temperatures during the late stages of pregnancy utero are strongly correlated with shorter gestational lengths (Basu et al 2010). If late-term temperature is correlated with pre-term delivery, and pre-term delivery is correlated with worse human capital outcomes as adults, this would bias the coefficients on temperature shocks during the third trimester down and also cause the true conception effect to appear at 8 months before birth, biasing the coefficient at 8 months in the direction of the true conception effect and the coefficient on the effect at t-9 in the opposite direction. Unfortunately, there is no way in our data to measure gestation length, so one must interpret our results with caution.

\section{Data}

We use two general types of data in this paper: data on temperature and data on outcomes. Our outcomes data come from two different sources: African Census data from IPUMS International, and survey data from the MEASURE DHS program. In addition, the analysis of one of our mechanisms uses an additional data set on Google search frequency in sub-Saharan Africa. We introduce each of these data sets in this section.

\subsection{Temperature Data}

In this paper, we use the gridded temperature dataset from Willmott and Matsuura (2012) housed at the University of Delaware, hereafter referred to as UDEL. These data are created by projecting temperature data from a large number of weather stations reported in the Global Historical Climate Network $(\mathrm{GHCN})$ onto a $0.5 \times 0.5$ degree global grid. Table 1 contains some descriptive statistics for our sample. Panel A indicates that the average temperature at conception in our sample is $22.9^{\circ} \mathrm{C}$. The standard deviation of temperature is small at only $0.759^{\circ} \mathrm{C} .{ }^{10}$ In addition, the average amount of precipitation

\footnotetext{
${ }^{10}$ This standard deviation is for the temperature "shock" - the demeaned (by region-month) average temperature. This gives us a better sense of the size of the random temperature shocks than the unconditional standard deviation of temperature, which is necessarily higher due to differences in climate across space and seasons. The unconditional standard deviation is $3.01^{\circ} \mathrm{C}$.
} 
is $102.1 \mathrm{~mm}$, with a standard deviation of precipitation shocks of $42.3 \mathrm{~mm}$.

Appendix A provides additional information on the nature of the temperature data. Temperatures in Africa are generally warm with a very low variance compared to more temperate regions. In figure $\mathrm{A} 1$, we see that a large fraction of the monthly temperature observations cluster in the low 20s Celsius, with temperatures rarely exceeding 30 degrees. In addition, the temperature deviations are generally very small and approximately normally distributed. Approximately 95 percent of the temperature observations do not deviate from the average temperature for that month-region by more than plus or minus 2 degrees Celsius. As a result, it is important to understand that we are identifying our effects off of relatively small deviations - large deviations may have different and perhaps non-linear effects on outcomes.

Much of the literature on climate change suggests that temperature shocks are becoming larger over time and as temperatures rise. Since this assumption may have some implications for the policy relevance of our analysis, we tested this assumption in Table A and Figure A2. Table A regresses the size of the temperature shock on the level of temperature and year in a given region-month controlling for region and month fixed effects. The temperature shocks are measured in absolute value from the mean in order to better estimate the variance of these shocks. We find that, indeed, the size of the temperature shocks are becoming larger over time. In addition, we do find that higher temperatures are positively correlated with larger temperature shocks in our data.

\subsection{Census Data}

Our Census data for sub-Saharan African countries are from IPUMS International. By necessity we restrict our analysis to the countries which have data on region of birth, year of birth, month of birth, and at least one outcome of interest. In general, the constraining variable is the month of birth, which is missing for the majority of countries. We are left with nine Censuses in six countries for our analysis - Burkina Faso (1996 and 2006), Cameroon (1976 and 2005), Guinea (1996), Malawi (2008), Rwanda (1991, 2002), and Uganda (2002). 
Using ArcGIS and sub-national shape files from IPUMS, we overlay the UDEL $0.5 \times 0.5$ degree global grid onto the sub-national regions in the Census to generate a monthly panel of temperature corresponding to our Census regions. ${ }^{11}$ Then using the region, month and year of birth given in the Census, and assuming that people are conceived nine months earlier in the same region they are born in, we can find the temperature at conception for each individual in our Census sample.

Our regions in the IPUMS Census data correspond with the GIS GEOLEV1 subnational level, which represent the first sub-national government administrative level in a country. For Burkina Faso and Guinea the administrative unit is called the Region, for Cameroon and Rwanda it is the Province, and for Malawi and Uganda the District. There are a total of 130 regions - 13 for Burkina Faso, 10 for Cameroon, and 8, 31, 12 and 56 for Guinea, Malawi, Rwanda, and Uganda respectively. The Census regions are also held constant over time. For example, in 2006 the Rwandan government reduced the number of administrative regions from 12 to 5, but the Census still uses the 12 older, smaller administrative regions for consistency over time.

Table I, Panel B lists the three main outcomes we use from the Census data. For education, we use a measure for years of schooling which we impute from educational attainment. ${ }^{12}$ The average individual in our sample has attained the equivalent of 5.23 years of schooling. Literacy and No Disability are indicator variables which take a value of 1 if the individual is literate or not disabled. ${ }^{13} 72.3$ percent of individuals in our sample are literate whereas 97.2 percent are not disabled.

One problematic area for using disability as an indicator for health status is that there is no systematic definition of a disability across countries in the Census data - it only matters that one report that they have a disability. For example, in Guinea the Census

\footnotetext{
${ }^{11}$ The temperature of each Census region is calculated as the weighted average of all the grid cells which fall into that region, where the weight on each cell corresponds to the fraction of the total area of the region contributed by the grid cell.

${ }^{12}$ The Census data give very detailed educational attainment data which allows us to estimate the number of years of education attained with a high level of certainty. For example, rather than only reporting broad categories (such as primary, some primary, etc.), they report the actual number of years of primary, secondary, university, or trade school education.

${ }^{13}$ We invert the indicator for disability to be a 1 if the individual is not disabled so that a positive coefficient means a better outcome, consistent with the rest of our outcomes.
} 
asked about a major disability, physical or mental, that limits normal activities. However, in Uganda disability was defined in terms of the ability to lead a normal social and work life. It is easy to speculate that various types of disabilities, such as temporary vs. permanent, physical vs. mental, etc. may be misreported by the individual respondents due to the ambiguity and inconsistency of the definition of disability. Few countries in our sample ask about specific types of disabilities. As a result, caution must be exercised when interpreting the meaning of our disability results.

Since young children will have no variation in the number of years of schooling attained (since they are too young to attend school), we only keep individuals who are old enough to show some heterogeneity in school attendance. Since a large fraction of children drop out after receiving only a few years of education, we observe a significant amount of heterogeneity in years of schooling by age 10, and drop individuals younger than this age. $^{14}$

\subsection{DHS / MIS / AIS Data}

Since the number of variables in the Census is very limited, we augment our outcomes data using the Demographic and Health Surveys (DHS), Malaria Indicator Surveys (MIS), and AIDS Indicator Surveys (AIS) for a set of countries in sub-Saharan Africa between 2000 and 2014. DHS / MIS / AIS samples are drawn from geographical clusters. These clusters are obtained from the previous Census enumeration areas and are nationally representative. The data contain detailed information on the health of children and women as well as household characteristics. Using these data, we investigate the role of temperature at conception on mortality, as well as explore specific channels which may be driving the correlation between temperature and outcomes.

The data contain information on the region of residence of each individual. These regions for the most part correspond with the GEOLVL1 regions used in the Census the first level administrative sub-national region. However, there are some cases where

\footnotetext{
${ }^{14}$ Since we have year of birth fixed effects, the fact that these individuals may not have completed schooling is inconsequential: we are essentially testing for heterogeneity in schooling within each age cohort.
} 
finer-level geographic information is given. In our analysis, a region is the smallest area that we can follow over time. We generally use the "hv024" variable to construct our region variable. ${ }^{15}$ Within countries, the boundaries of regions may change over time. In these instances, we combine regions using maps provided in the public report of each survey. The regions enable us to merge the DHS data with the temperature data as we did with the Census data.

A detailed list of the DHS data sets used in this analysis is provided in Table B in the Online Appendix. The number of surveys per country varies between one (for four countries) and six (for Senegal). ${ }^{16}$ The number of regions in a country ranges from four to 26 . In total, the sample contains 326 regions.

Using the DHS / MIS / AIS, we first investigate the relationship between temperature at conception and mortality in childhood using information on women's birth history. We focus on five different outcomes: mortality before 12 months, between 12 and 24 months, between 24 and 36 months, between 36 and 48 months, and between 48 and 60 months. Specifically, to analyze mortality before 12 months, we use the sample of children born in the 12 months preceding the interview and our outcome of interest is an indicator variable for whether the child is dead at the time of the interview. To study mortality between 12 and 24 months, we use the sample of children born 12 to 24 months before the interview, who were alive at age 12 months, and our dependent variable is a dummy for whether they are dead at the time of the interview. The remaining samples and outcomes are defined in a similar way. Table I, Panel C, shows that 5.2 percent of children born to women in the year preceding the interview have died by the time of the survey.

When we explore the channels relating temperature and outcomes, we pay particular attention to the mother's education and to household wealth. The mother's education variables are dummies indicating whether the mother completed at least primary education and whether she completed at least secondary education. For household wealth, we

\footnotetext{
${ }^{15}$ However, whenever the data contain information on smaller areas, such as states, zones, counties, and provinces, we also use it. The corresponding variables' names are "shstate," "shnewzon," "shcnty," "sh002," "sh006," and "hv023," depending on surveys.

${ }^{16}$ Countries with one single survey, for which we cannot follow "region-month"s over years, are used in the analysis of sexual behavior.
} 
employ dummies for whether the household has access to an improved source of drinking water or to improved sanitation facilities. ${ }^{17}$

Information on sexual activity is available for women ages 15-49. They are asked whether they were sexually active over the four weeks preceding the interview. The response categories are the following: (0) never had intercourse; (1) active in last 4 weeks; (2) not active in last 4 weeks - postpartum abstinence after the birth of the last child; (3) not active in last 4 weeks - not postpartum abstinence after the birth of the last child. "Postpartum" means that the woman declares that she has been abstinent since the birth of her last child. When studying sexual activity, we keep women who never had intercourse but drop women who are postpartum. Our outcome of interest is a dummy for whether the woman was sexually active. According to Table I, Panel C, 56.7 percent of women were sexually active.

We also check the role of terminated pregnancies and sexual activity in the relationship between temperature at conception and outcomes. Information on terminations come from calendar variables indicating whether a woman was pregnant, gave birth, or was using birth control for each month for 60 months before the interview. We restrict our sample to pregnancies with conception between the 31st and the 9th month before the interview (i.e. children who were born during the two years preceding the interview, and pregnancies which would have resulted in a live birth during the two years preceding the interview had the child remained alive). ${ }^{18}$ The termination variable is a dummy that indicates whether that pregnancy ended in a termination. Terminations include both spontaneous and induced abortions - the data do not distinguish between these two types of termination. Table I indicates that 7.8 percent of pregnancies ended in termination.

\footnotetext{
${ }^{17}$ Following the World Bank, we define an improved water source as any of the following sources: piped water into dwelling, piped water to yard/plot, public tap or standpipe, tubewell or borehole, protected dug well, protected spring, and bottled water. Improved sanitation facilities are defined as a flush toilet, a piped sewer system, septic tank, a flush/pour flush pit latrine, a ventilated improved pit latrine (VIP), a pit latrine with slab, or a composting toilet.

${ }^{18}$ Note that the calendar data is missing in a number of countries, so the sample we use to study terminations is smaller than the sample to study mortality.
} 


\subsection{Google Data}

To test the effect of temperature on sexual activity, we supplement our analysis with data on Google searches of sexually-themed words. Markey and Markey (2013) analyze Google searches for 25 sexually- or romantically-themed keywords from 2006 to 2011, and compare them with 21 control keywords. They find that searches for sexuallythemed keywords exhibited seasonal variation in the United States. We employ a similar methodology.

Google Trends (http://www.google.com/trends/) enables users to download weekly data on the frequency of keyword searches by geographic area. In the United States, the geographic units can be as fine as an MSA, but in Africa internet connections are more rare. As a result, the finest geographic region is generally the entire country. Since the DHS and Census regions are subnational, we recalculated the UDEL temperature data at the national level using ArcGIS, then merged them with the Google search data. This resulted in a country-level panel dataset on monthly Google searches for each of the 46 keywords in Markey and Markey (2013).

We restrict our analysis to only five of the 46 keywords in Markey and Markey (2013) - sex, porn, Hotmail, Google, and Yahoo - since these are the only keywords for which there are five years or more of data. Rather than reporting an absolute measure of the number of searches for keywords, Google reports an index. We normalize each keyword's index to equal 100 at the mean frequency of searches over the five-year sample, allowing us to interpret the coefficients as the percentage change in searches from the mean.

\section{Results}

To explore the correlation between temperature at conception and outcomes later in life, we begin by estimating equation (1) using a number of educational and health outcomes. We use two different measures of educational attainment as our dependent variables: imputed of years of schooling based on educational attainment and a dummy for whether 
the individual is literate. ${ }^{19}$ To measure health outcomes, we have two main metrics. The first measures health status directly by using an indicator variable which takes the value of one if an individual reports having no disability in the Census data, while the second uses child mortality in the DHS/MIS/AIS data.

\subsection{Educational Outcomes}

We find that temperature at the time of conception is positively correlated with our first measure of educational outcomes - the imputed years of schooling based on educational attainment. We report our results in Table II, columns (1) and (2). Column (1) shows results using just the temperature deviation nine months before birth, and finds that an increase in the average monthly temperature of one Celsius degree is associated with an increase of approximately 0.0317 years of schooling. Since the standard deviation of temperature in an average region-month in our sample is 0.759 degrees, and the average level of schooling is 5.23 years, this implies that a one standard deviation increase in temperature increases years of schooling by 0.46 percent at the mean. While temperature is by no means the main driver of educational attainment, this result suggests that temperature spikes do have an economically significant impact.

Column (2) expands the analysis from column (1) by adding controls for temperature deviations in every month from 15 months before birth to 3 months after. In addition, given the large literature on the effects of precipitation in Africa, we also add a full set of precipitation controls - one for each month from 15 months before birth to 3 months after birth - instead of just one for precipitation nine months before birth as in column (1)..$^{20}$

Beyond robustness, including these other temperature variables are useful for four

\footnotetext{
${ }^{19}$ There is an additional measure of education - raw years of schooling attended independent of attainment - which is also available in the census data. We ran our analysis using this additional outcome, and the results were essentially identical to the results for years of schooling based on attainment. Since we felt attainment more closely captures educational capital than raw years of schooling, and since the results of our analysis was essentially identical for both measures, we ended up dropping them from our analysis for the sake of brevity. However, they are available upon request.

${ }^{20}$ The correlation between rainfall and temperature in our data set is -0.034 , implying that it becomes slightly cooler when it rains. Although this correlation is somewhat small, it is still highly statistically significant.
} 
reasons. First, since gestation lengths are highly variable, and many births occur eight or ten months after conception, one may be concerned that only including temperature at nine months before birth does not measure temperature at conception precisely. We may identify effects of conception both at 10 months before birth and 8 months before birth to account for late and early deliveries respectively. Second, if temperature shocks are highly persistent month-to-month, a shock at the time of conception could be correlated with a temperature shock earlier or later in the pregnancy. In this case, we could be picking up the effect of early in utero exposure to temperature on the coefficient for temperature at the time of conception. ${ }^{21}$ Third, it enables us to test whether temperature shocks before birth may affect later life outcomes by affecting conditions immediately before the mother conceives, such as weather shocks which affect crop failures and hence nutritional intake over the course of the next year. Finally, it allows us to explore the effect of temperature in utero and in early life.

In Column (2) of Table II we find statistically significant effects at nine months before birth as in column (1), but only at the 10 percent level. Interestingly, however, we find an even larger effect at 8 months before birth than at 9 months - approximately 60 percent larger $(0.0158$ vs. 0.0256$) .{ }^{22}$ There are two ways to interpret this result. First, since temperature shocks have been correlated with shorter gestation lengths, and since gestation length is a random variable, it may be the case that some of the effect of conception is spilling over onto the coefficient on $\mathrm{t}-8$. However, if that were the case, we would expect the coefficient to be smaller on t- 8 than on t-9 since more births occur during the 9 th month relative to the 8 th. Second, it may be the case that not only temperature at conception matters, but also temperature in early pregnancy. This is the interpretation we favor, since we also see a positive and statistically significant coefficient at the 5 percent level on temperature 7 months before birth.

\footnotetext{
${ }^{21}$ We also estimate an $\mathrm{AR}(10)$ model on monthly temperature deviations and find that the first order AR coefficient is approximately 0.3 , the second order coefficient is 0.06 , and the third through tenth coefficients vary from 0.01 to 0.05 . All the coefficients are statistically significant, implying that while temperature deviations do not persist much after one month, there still is some small yet detectable level of autocorrelation even after many months. We also estimate a model with leads instead of lags and find similar results. E.

${ }^{22}$ These dynamic results, along with our other main results, are also visualized in figures in Appendix
} 
In Columns (3) and (4) we repeat our analysis for literacy rates. We find a similar pattern as we did for educational attainment, only here our results are even stronger. In column (3), we find that a one-degree monthly average temperature shock nine months before birth increases the probability of being literate by 0.355 percent. This implies that a one standard deviation shock in monthly average temperature nine months before birth increases literacy by 0.37 percent, which is very similar to our effect on educational attainment. Again we find a very significant result 9 months before birth, but an even larger coefficient on the 8th month before birth. (0.00204 vs. 0.00286). We also find significant effects for the 7 th and 6 th month before birth.

In contrast to our educational attainment results, we find more support for the idea that the conditions right before and after birth may be important as well. For example, we are now picking up statistically significant effects each month in the third trimester. These affects appear to be slightly smaller in magnitude than the effects at conception and early pregnancy, but still somewhat similar in magnitude. This is consistent with the findings of Kudamatsu et al. (2012) who find that temperature shocks immediately after birth in malarious and drought-prone regions of Africa lead to higher infant mortality. Since weaker children (or children from low-income parents) may be disproportionately affected by a poor mortality environment, those who survive may have better characteristics on average.

We also find stronger evidence for effects before pregnancy as well. One potential cause for this may that if warmer months affect crop production (e.g. drought) during a pivotal month of the growing cycle, this may affect food security and hence nutritional intake for the entire subsequent year. As a result, we may find an effect of temperature in the months leading up to a woman becoming pregnant. We return to this point in Section 5.3 where we look for heterogeneous effects based on temperature deviations during the growing season and non-growing season (i.e. rainy vs. dry season), and find that temperature in the rainy season affects later life outcomes to a larger extent in every month before, after, and during pregnancy - suggesting that our temperature effects may be primarily caused by food availability. 


\section{$4.2 \quad$ Health Outcomes}

Columns (5) and (6) of Table II, present our results on disability. We find no systematic evidence that temperature shocks at any time before, during, or after conception matters for disability status. However, given the subjectivity surrounding how disability is defined across surveys and the low rates of disability reported in the Census (2.1 percent of the sample reports having a disability), this is perhaps understandable.

We also find that temperature shocks at the time of conception do not mortality for children once they are born. Using the birth history of women from the DHS / MIS / AIS data, we run separate regressions for child mortality by year until age five. Specifically, the five columns in Table III correspond to regressions where the dependent variable is a dummy for death between 0 and 12 months, 12 to 24 months, 24 to 36 months, 36 to 48 months, and 48 to 60 months respectively, dependent on the temperature the child experienced around the time of conception and in utero. In Panel A, we only control for temperature 9 months before birth, and although most coefficients are negative, none of them are statistically different from zero. For example, since the average infant mortality rate in our sample is 5.2 percent, our coefficient of -0.0006 implies that a one-standard deviation temperature shock reduces infant mortality by a statistically insignificant 0.71 percent - similar to the effect sizes for years of schooling and literacy. ${ }^{23}$ Similarly, in Panel B, we include the full set of temperature variables. We find similar results to those in Panel A - the coefficients of temperature nine months before birth is generally negative and statistically insignificant.

\section{Channels}

In the previous section, we established that temperature spikes at the time of conception are associated with better educational attainment and literacy. In this section, we seek to

\footnotetext{
${ }^{23}$ In reality, the infant mortality rate is closer to 10 percent in sub-Saharan Africa. The discrepancy comes from the fact that in our sample, we do not observe all children between 0-12 months at precisely the age of 12 months. For example, we may observe a child who is six months old, who is still alive when we observer her, but who still may die before the age of one. As a result, the mean of our dichotomous mortality variable should be precisely half the true mortality rate if the distribution birth-months of observed children is uniformly distributed throughout the year.
} 
answer why these correlations exist. We focus on two possible explanations: (1) selection of parents with different human capital and wealth characteristics into conception based on ambient temperature, and (2) heat-dependent selection on the health of the fetuses themselves. For each channel, we begin by explaining the theoretical reasons for the mechanism, and then provide evidence for or against it. We conclude this section by discussing other possible explanations we were unable to test with our data.

\subsection{Selection on Parental Characteristics}

Temperature may induce different groups of women to become pregnant at different times, either intentionally or unintentionally. For example, Buckles and Hungerman (2013) show that there is a significant amount of seasonality in educational attainment and marital status of childbearing women. Children born in winter are more likely to have a mother who is a teenager, have low education, or be single. One possible explanation for their finding is temperature. Hot temperatures may reduce sexual activity (Barreca et al. 2014, Lam and Miron 1996). These reductions may be disproportionately large for those unable to invest in technologies to shield themselves from the heat (e.g. air conditioning). As a result, fertility may fall faster nine months after a period of elevated temperature among women with lower education and socioeconomic status. This would change the mix of women conceiving children during temperature spikes, inducing a correlation between maternal characteristics and temperature at conception.

Temperature may also affect fecundity heterogeneously for women of different socioeconomic groups. For example, increased body temperature may negatively impact ovulation and lead to irregular menstruation or failed implantation. Temperature also affects male fecundity through lower semen quality and testosterone levels. ${ }^{24}$ If the fecundity of lower socioeconomic status women is disproportionately affected by temperature spikes (either directly or through their partners), this could lead to a lower number of births by less educated and poorer women. Both of these channels may affect the mix of women who conceive during periods of elevated temperatures, causing the average child

\footnotetext{
${ }^{24}$ See Barreca et al. (2014) for an extensive review of the literature on temperature and fecundity.
} 
conceived during a temperature spike to have a mother with better characteristics, and thereby better outcomes later in life.

It is important to note that selection on parental characteristics should mostly explain the difference in outcomes based on temperature around the time of conception, since it primarily affects the mix of parents who select into conceiving a child at any given time. Estimated effects of temperature before pregnancy and during pregnancy should therefore have a different explanation, even if those explanations may interact with parental quality, as in the case of fetal selection discussed in section 5.2 and food insecurity in section 5.3.

\subsubsection{Sexual Activity}

We begin our analysis by testing whether sexual activity during periods of elevated temperatures depends on socioeconomic status. Using the DHS / MIS / AIS data, we regress a dummy for whether a woman was sexually active in the four weeks preceding the interview on temperature during and up to two months before the interview. In this case, our identification strategy is the same, but is implemented slightly differently. Because in the DHS / MIS / AIS data, each country's surveys in different years are not always carried out during the exact same months, we are not always able to follow a "Region-Month of Interview" over several years. For this reason, to explore the relationship between temperature and sexual activity, we do not estimate a model with "Region-Month of Interview" fixed effects. Instead, we demean the temperature data beforehand, by calculating the temperature for the month of interest minus the average temperature in the "Region-Month" using the UDEL temperature series. In short, since we cannot rely on region-month fixed effects, we demean the data first to achieve the same result.

The estimation results are given in Table IV. We find that sexual activity decreases with temperature in the month before the interview (which is the month they would be reporting their sexual behavior about), consistent with the fall in fertility found in Barreca et al. (2014) and Lam and Miron (1996). Our results are extremely consistent across all the specifications. We also test to see whether the fall in sexual activity is larger for women of a higher socioeconomic status. We use three indicators of socioeconomic 
status common across all the DHS surveys: one indicator variable for whether the woman completed at least primary education, and two indicator variables measuring aspects of wealth - improved sanitation and improved water. We find no effect for the interactions with any socioeconomic variables. Using the coefficients from column (5), our results imply that a one standard deviation temperature shock reduces the extensive margin of sexual activity by 1.06 percentage points.

We augment our analysis of the extensive margin of sexual activity with data on the frequency of internet searches for a series of sexually-themed words in sub-Saharan Africa. If reductions in sexual activity occur due to lower libido during temperature spikes, we should find that demand for other sexual activities (such as looking at pornography online) falls temperature spikes as well. To measure Google searches, we use data from Google Trends for the two sexually-themed keywords ("sex" and "porn") and the three control keywords ("Hotmail," "Google," and "Yahoo") used in Markey and Markey (2013) which have at least five years of data.

In Table $\mathrm{V}$, we find that temperature spikes reduce the frequency of searches for sexually-themed words. Columns (1) and (2) show that a one standard deviation increase in temperature reduces searches for "sex" by 1.56 percent and "porn" by 2.29 percent. Each regression includes region-month fixed effects, as well as controls for the three control words measuring general internet usage. Since we normalize the searches to be 100 at the mean level of searches, the coefficients in Table $\mathrm{V}$ can be interpreted as percentage changes from the mean. Column (3) aggregates searches for the two sexually-themed words together, and the three control words together, and regresses the aggregated sexual words index on temperature and the aggregate internet use index. We find a similar decrease in the search frequency of sexually themed words by 1.80 percent. Finally, in column (4) we take the ratio of the sexual searches index and the control index to create an index of sexual searches normalized by the control searches, since temperature may also affect the amount of internet use. We find that a one standard deviation increase in temperature decreases aggregate searches for "porn" and "sex" by 4.15 percent. 


\subsubsection{Parental Characteristics}

Next we test directly whether mothers who conceive when temperature is higher than normal have higher levels of human capital and wealth. To test this channel, we regress a series of maternal outcomes from the DHS / MIS / AIS data set on the temperature when women conceived their children. The results are reported in Table VI. We do not find that parents who conceive during periods of high temperatures are of a higher socioeconomic status than those who do not. Specifically, we find they are no more likely to have attained a primary or secondary education, or have an improved source of drinking water. In fact, we actually find that they are less likely to have improved sanitation. Therefore, our findings do not support that differences in parental socioeconomic and educational status drive the correlation between temperature at conception and later life outcomes.

We then analyze whether the effect of temperature on education and health outcomes remains significant after controlling for parental characteristics. Unfortunately, there is no information in the Census data on parental characteristics, except for adults who live in the same household as their parents. Approximately $1 / 4$ th of the sample falls into this category. Although this subset is likely unrepresentative of the population as a whole, we re-run our original analysis from Tables II and III with this smaller sub-sample while controlling for both mother's and father's education in the case of the census, and for the wealth and the education level of the mother in the DHS / MIS / AIS (in the subset of cases where we have information on those variables). It should be noted that while in the Census, this reduces our sample by approximately 75 percent, it only reduces our sample in the DHS by about 10 percent.

We report our results in Table VII. Unfortunately, in the highly selected Census sub-sample we can no longer detect significance of our main results, but controlling for parental characteristics do not significantly change our results. We conclude that, although we do find some evidence that selection into pregnancy does occur due to elevated temperatures, differences in these parental characteristics do not satisfactorily explain why above average temperatures at conception are correlated with outcomes later in life. 


\subsection{Selection on Fetal Strength}

The positive correlation between temperature at conception and later life outcomes may be due to selection in utero. If weaker fetuses are more likely to die in utero due to a temperature shock, then the stronger, healthier fetuses are more likely to survive, potentially leading to a more educated and healthier population in adulthood. Not only could this channel affect survival - and hence outcomes - of zygotes around the time of conception, but also at later months in utero as well. It could even induce a correlation between outcomes and temperature before the time of conception, inasmuch as the health status of the mother in the months immediately proceeding conception dictate the survival probabilities of the zygote during conception and of the fetus later in utero. However, spontaneous abortions are difficult to measure, since over 50 percent of spontaneous abortions occur before the mother knows she is pregnant (Liu et al. 2014).

We test the fetal selection channel in three ways. First, using a pregnancy outcome questionnaire in the DHS / MIS / AIS, we regress an indicator which takes a value of one if a pregnancy is terminated before birth for any reason on temperature three months before the month the woman first reports being pregnant (MRP) to one month after. The results are reported in Table VIII. The estimates provide evidence that temperature around the probable time of conception (one to three months before she first reports being pregnant) is negatively associated with termination. For example, the coefficient in column (2) of Table VIII implies that a one standard deviation increase in temperature decreases the probability that a women experiences a known termination before birth by 0.45 percentage points. Since 7.8 percent of women in our sample experience a termination, this implies a 5.8 percent decrease in terminations.

There are two interesting observations about this finding. First, this reduction is quite large. In addition, finding a decrease in terminations seems to contradict our hypothesis that fetal loss should increase during temperature spikes. However, that would only be true if the termination variable correctly measured fetal loss. In columns (1) and (4), we show our termination variable is actually positively correlated with education and wealth. If the termination variable was driven by fetal loss, those coefficients should 
have been negative. But we do know that induced abortion is positively correlated with income and education in Africa (Rominski et al. 2014). Since the termination variable does not distinguish between spontaneous and induced abortion, we believe that the termination variable is more likely measuring induced abortions rather than fetal loss through spontaneous miscarriages. In addition, this analysis is not fully satisfying since it only measures known terminations, whereas most terminations occur very early in pregnancy before the mother even knows she is pregnant.

Second, we test for fetal loss by investigating the effect of temperature on the sex ratio. Since males require more maternal resources to form and carry full term than females and tend to be more fragile in utero, during periods of fetal stress the gender ratio skews female (Catalano et al. 2005, Catalano et al. 2006, Catalano and Bruckner 2006, Liu et al. 2014, Hernàndez-Juliàn et al. 2014). Using our Census data, we regress an indicator variable for whether the child is female on the temperature at conception, restricting our sample to individuals less than the age of 2 to reduce the bias from selective mortality after birth. Our results are presented in Table IX. Column (1) presents the results only using temperature nine months before birth as the variable of interest, while Column (2) uses the full set of temperature controls. We find that temperature 9 months before birth skews the gender ratio female. Specifically, a one Celsius degree increase in average monthly temperature increases the fraction of females born by 0.249 percentage points. This corresponds to a one standard deviation increase in temperature increasing female births by 0.37 percent. This provides support for our fetal loss hypothesis, and implies that weaker fetuses are being selected out when temperature is higher than normal at the time of conception. The surviving stronger fetuses are then more likely to have better outcomes as adults.

Finally, we test for heterogeneous effects of temperature at conception on outcomes by gender. If temperature spikes select out a larger fraction of males than females, then the mean health of the remaining male fetuses should be better than for females since they were subject to stronger selective pressure in utero. As a result, we would expect the effect of temperature at conception on outcomes to be stronger for males. In Table X 
we find this exact result. We regress each of our three Census outcomes on temperature at the time of conception, a dummy for being a female, and the interaction of female and temperature at the time of conception. A negative coefficient on the interaction term suggests that the temperature effects are smaller for females - consistent with the theory that fetal loss is driving the results. For our education measures, the effect of a one Celsius degree increase in temperature at conception for males is almost exactly double the effect for females. This corresponds with a one standard deviation temperature shock at the time of conception increasing male educational attainment by 1.9 percent and male literacy by 1.0 percent from the mean, compared with an increase of female educational attainment of 0.95 percent and an increase in female literacy by 0.45 percent from the mean. In addition, whereas we never picked up significance on our disability variable before, we find that, for males, there is now a statistically significant effect for male disability, but not for female. A one standard deviation increase in temperature shocks at t-9 reduced disability by 2.01 percent from the mean for males, significant at the 5 percent level, while for females there is only a statistically insignificant 0.14 percent reduction from the mean.

\subsection{Other Mechanisms - Food Insecurity, Agricultural Produc- tion, and Cohort Size}

A few additional theories of how temperature at conception may affect outcomes are worth mentioning. First, temperature spikes at conception may be correlated with income, especially in sub-Saharan Africa where a sizable fraction of the population is employed in subsistence farming. ${ }^{25}$ This lower income at the time of conception may lead to poorer nutrition and maternal health, thereby affecting the probability of conception or implantation, as well as damaging the fetus. ${ }^{26}$ Just as in the case of fetal selection as

\footnotetext{
${ }^{25}$ While Dell, Jones, and Olken (2012) and Hsiang (2010) find that temperature in North American and the Caribbean is negatively associated with income, Barrios, Bertinelli, and Stobl (2010) do not find an effect in sub-Saharan Africa. Instead, they find that income is much more sensitive to rainfall, similar to the findings of Brückner and Ciccone (2011). Focusing just on agricultural output, Schlenker and Lobell (2010) do find a negative effect of temperature on crop yields in sub-Saharan Africa.

${ }^{26}$ Poor nutrition could also result from general equilibrium effects of temperature, such as increases in food prices.
} 
discussed in section 5.2, this channel could theoretically also induce a correlation between temperature at any point pre-conception, during conception, and later in utero and later life outcomes: food insecurity could affect the health status of the mother, which could have long lasting effects, especially if it occurs during seasons pivotal for agricultural production.

While this channel is not directly testable using our data, implications of this pathway are. If our effect were running through reduced agricultural production and food insecurity, then temperature should only matter during months pivotal for agricultural production, not year round. ${ }^{27}$ Higher temperatures in one month resulting in a poor harvest would affect prices, incomes, savings, and production (and thereby nutrition) for months afterward, not just during the month of elevated temperatures.

We test this hypothesis in a series of five tables in the online Appendix C. We first begin by splitting the sample into two groups - those in which the month of conception is during the rainy season (the season which is the most food insecure, and the most pivotal for agricultural production) and the dry season. ${ }^{28}$ Table $\mathrm{C} 1$ reports the results for the rainy season, while $\mathrm{C} 2$ reports the results for the dry season. In Table $\mathrm{C} 1$, we find that the results hold an almost identical pattern to the overall results, except that the magnitudes are significantly larger. In the overall sample, the effect of a one degree monthly temperature deviation nine months before birth (Column (1) of Table 2) was 0.0317 , while in the rainy season only sample it is 0.0527 . Similarly, the effect of temperature eight and seven months before birth was 0.0256 and 0.0193 in the full sample respectively, while in the rainy season only sample it is 0.0385 and 0.0286 . This represents an over 50 percent increase in the coefficient size, suggesting that temperature deviations during more food insecure times of year have larger effects. A similar pattern is found for literacy - the effects occur at the same months but with a larger magnitude - and for disability where there are no effects in either sample.

\footnotetext{
${ }^{27}$ Our results are average treatment effects of temperature over all months in the year, not just these pivotal windows.

${ }^{28}$ We define the rainy season as the set of months with above average rainfall for that region. Specifically, we find the average rainfall for each of the 12 months across all years in our sample for each region. Then we assign the rainy indicator to equal 1 for those months which are above the average rainfall across the 12 months of the year.
} 
The sample in which the time of conception happens in the dry season, however, displays a different pattern. The coefficient on temperature at conception and early pregnancy are still positive and significant, but only for literacy. The magnitudes sizes are also much smaller. For educational attainment, the coefficient sizes become so small that the result is no longer significant at the 10 percent level. We also see a pattern of significant results during different months than in the full sample - temperature deviations during the 14th and 15th month before conception are now large positive and significant, and even larger than the effects during conception and early pregnancy. In addition, the coefficients on the 2nd, 3rd, and 4th month before birth are now large, positive, and significant as well. While these results may seem counterintuitive to the rest of our findings, they are actually consistent with what we would expect if we believe that the rainy season matters for food security. In this sample, month t-9 is during the dry season, which implies that month t- 3 and t- 15 are during the rainy season. For example, if month t-3 is a food insecure month, and food insecurity had adverse effects on nutritional intake in utero and contributes to fetal loss, then we may see large and positive effects of temperature shocks around this month. Similarly, if the rainy season is important for agricultural production, then a temperature shock at month $\mathrm{t}-15$ may reduce the size of the harvest and hence nutritional intake for the subsequent year, leading to higher rates of fetal loss. As a result, it appears that temperature shocks during the rainy season independent of their timing in relation to in utero exposure - may have positive effects on outcomes later in life.

To test this conjecture, we rerun our main results from Table II, but this time we also include interaction effects between the temperature deviation and a dummy for whether than particular month was during the rainy season. The results are found in Table C3. We find that the coefficients on the interactions between the temperature deviation and the rainy season are large, positive, and statistically significant for almost every coefficient from 6 months before conception to the 8th month of pregnancy (t-15 to t-2). This result suggests that temperature deviations during rainy seasons, independent of when they occur, are much more impactful on maternal and in utero health. This result also lend 
credibility to the hypothesis that perhaps temperature shocks are not directly responsible for the negative in utero health conditions, but rather are only impactful through their effects on nutritional intake.

Note that this result does not undermine our previous conclusions about fetal loss. In fact, poor nutrition at the time of conception or in utero may be the precise driver of the intensified fetal loss, increasing the average human capital of the surviving cohort. In order to test this hypothesis, we re-estimate Table C3, but use the gender ratio as the dependent variable, similar to our test of fetal loss in table IX but augmented to find heterogeneous effects by rainy/dry season. Our results are found in Table C4, and visualized in Figure $\mathrm{C}$ in the appendix. We find that temperature shocks induce changes in the gender ratio similar to the pattern found in Table C3, consistent with fetal loss being the main driver of better outcomes later in life. It is also interesting to note that temperature shocks during the growing season affect the fetal loss of children not yet conceived, consistent with the hypothesis that the main channel causing the fetal loss is food insecurity caused by a bad harvest.

We also test to see whether we find similar differences in infant mortality between rainy and dry seasons. In Table C5, we again divide our sample between whether the month of conception occurs during a rainy month or a dry month as in Tables C1 and C2. Columns (1) and (2) test the effect of temperature shocks for the rainy season sample, while (3) and (4) run the same models but for the dry season sample. Similar to our results in Table III, we find no effect of temperature at any time before, during, or after conception on infant mortality.

Finally, it may be the case that our differential results between seasons may be caused by parental behavior selecting into pregnancy as conjectured in section 5.1. To test this, we re-run our sexual activity results stratified by the season in which the interview was taken, and report our results in Table C6. We find that there is no statistically significant difference in the effect of a temperature shock on sexual activity between the two seasons.

Another potential mechanism runs through cohort size. Since above average temperatures reduce fertility, cohorts of children conceived during periods of elevated temper- 
atures will be smaller. These smaller cohorts could have higher investment in human capital per capita after birth through public goods provision (smaller class sizes, less overcrowding of health clinics, etc.) or by moving parents along the quality/quantity frontier of child rearing. In addition, a smaller cohort may increase the returns to labor, thereby increasing wages of the affected cohorts which could lead to more human capital investments.

Cohort size effects are not likely to be the main driver of our results for three reasons. First, temperature spikes in this study are monthly deviations, which are too short of a time frame to significantly alter the demographic structure of society. A small monthly cohort conceived during a temperature spike would be put into the same school class as eleven other monthly cohorts, some of which would be born during normal temperatures and some during low temperatures. It is hard to believe that a one-month temperature spike would significantly alter the size of an annual school class. Second, the magnitudes of the fertility effect from Lam and Miron (1996) and Barreca et al. (2014) are much too small to significantly alter cohort size. For example, Barreca et al. (2014) find an additional 95 degree day (Fahrenheit) instead of a 65 degree day would reduce birthrates only by 0.7 percent. In our paper, this would translate into an increase in average monthly temperatures of 0.55 Celsius degrees, or a 0.72 standard deviation of temperature. As a result, a one standard deviation increase in temperature would reduce the size of the cohort by 0.97 percent. It is hard to believe that such a small decrease in cohort size could be responsible for the magnitude of the effects we find in this paper. Finally, labor is highly substitutable between cohorts, meaning we should not expect to find a significant difference in wages simply due to reduced labor supply in one monthly cohort.

\section{Temperature Non-linearities}

One shortcoming of our previous analysis is that it does not account for the potential non-linearities in temperature. Indeed, it is easy to imagine that a 5 degree increase in the average monthly temperature in a region which is usually 15 degrees Celsius should not 
matter as much as the same 5 degree increase in a region which is usually an average of 35 degrees. In addition, it is reasonable to think that the effect might also be non-linear in the size of the shock: a three standard deviation shock might have a exponentially higher effect than a one standard deviation shock. In the most recent literature studying the effects of temperature, temperature spikes are not measured in average monthly temperature as in this paper, but rather use daily measures of temperature which are then aggregated to the monthly level. For example, Holdaway, Wilde and Wilson (2016) and Deryugina and Hsiang (2014) analyse the effect of temperature on output in the United States by measuring the number of days in a year where the average daily temperature falls into a certain temperature bin, and then regress output on the frequency of days in each bin. This flexible non-parametric approach allows for arbitrary non-linear effects of temperature. Similar methods are found in Barreca et al (2014) which looks at temperature and fertility, Isen et al (2016) which looks at temperature in utero and wages in the US, and Ziven et al (2015) which analyzes temperature and test performance, in addition to many, many others.

Since this paper looks at the effect of temperature on long-run outcomes in subSaharan Africa, we cannot employ such methods because there does not exist any series of daily temperature data which extends back to the early 1900s for the region, which would be necessary for us to obtain temperature at birth for the individuals in our sample. ${ }^{29}$ In addition, even recent daily temperature observations for sub-Saharan Africa are sporadic and less ubiquitous than in other regions of the world, especially since the late 1980s when a sizeable fraction of the funding for weather stations in sub-Saharan Africa disappeared in the wake of the dissolution of the Soviet Union (see Dell et al 2014 for a more detailed discussion). Daily weather data is more scarce and unreliable in sub-Saharan Africa than in any other region in the world. As a result, we are limited to the monthly temperature

\footnotetext{
${ }^{29}$ There are some datasets which do contain daily weather data in sub-Saharan Africa, the most comprehensive being ERA-Interim which begins in 1979. However, since our most recent Census data is from 2008, using this temperature data set would artificially truncate our sample to individuals under age 29 at the absolute oldest, which is problematic for a paper attempting to look at long-run human capital outcomes. And since most of our Census data is actually from the mid-1990s, the problem becomes especially acute. In fact, one of the Censuses that we use begins in 1976 - before the earliest daily temperature series even begins.
} 
series, in which identifying flexible non-linear specifications is more difficult. Every other study on temperature in Africa of which we are aware also utilizes these monthly data series. ${ }^{30}$ However, allowing for non-linear effects is key for understanding the policy implications of research linking climate change and economic outcomes. If the negative effects of temperature shocks become increasingly larger as average temperatures rise, this could inform debates around the economic costs of climate change.

To begin to understand whether there are non-linear effects on long-run outcomes for temperature shocks at conception and in utero, we take the average temperature over all months and years for each region in our sample, and then stratify them into four groups. The first group contains regions whose average temperature is less than 20 degrees Celsius, the second group between 20 and 22 degrees Celsius, the third between 22 and 24 , and finally those regions for which average temperature is above 24 degrees. We then re-estimate our main Census results for each of these groups. The results are found in Figure D1 in Appendix D. Each sub-figure plots the coefficient on temperature 9 months before birth, along with the 95 percent confidence interval, for each of the four groups for each of the three outcomes. We find strong evidence for non-linear effects - the effect of temperature at conception is significantly larger for the group of regions with average temperatures above 24 degrees compared with the group with average temperatures below 20 degrees. For years of schooling, the increase is monotonic and almost linear across the four groups, rising 3.5 times from 0.0212 for the coldest group to 0.0707 for the warmest group. For reference, 0.707 is approximately double the effect from the entire sample from Table II Column (1). For literacy, the rise is also monotonic except for the last group which experiences a small decline in the effect, rising from a statistical zero to a coefficient of 0.0466 - over 10 times larger than the overall effect from Table II column (3). Given this strong evidence of non-linearities in educational attainment, we conclude that our results have significant relevance to the debate on the costs of climate change. Specifically, unless investments to adapt to rising temperatures are made, climate change will likely have significant adverse effects on maternal and in utero health of children.

\footnotetext{
${ }^{30}$ See Adhvaryu et al 2015 and Kudamatsu et al 2012 for recent examples.
} 
While Figure D1 provides evidence for non-linear effects based on the underlying temperature in the region, this analysis more likely speaks to the potential for adaptation or heterogeneity across regions. Another relevant question is to what extent do higher temperatures cause non-linear effects irrespective of underlying regional characteristics. In Table D1, we run our main specification for the effect temperature nine months before birth on outcomes, but include polynomials in temperature nine months before birth up to a quartic term. ${ }^{31}$ For years of schooling in Column (1), all four polynomial terms are highly significant, suggesting that the relationship between temperature at conception and education is highly non-linear. Using the coefficient values from Table D1, we visualize these results in the top panel of Figure D2 for the range of temperatures found in the Census data: 13-36 degrees Celsius. Consistent with the literature on the non-linear effects of temperature on outcomes, we find that the effect on educational attainment is basically very small and statistically insignificant until the temperatures reach the midto high-20s, and then begin to rise significantly thereafter. We repeat the analysis for literacy and disability status in Columns (2) and (3) in Table D1, and visualize them in the remaining panels of Figure D2. The non-linear effects on literacy mirror those for educational attainment, however they are not statistically significant. Consistent with our previous results, we find no non-linear effects for disability status.

Temperature shocks may also have non-linear effects based on the size of the deviation, independent of the underlying temperature level. We test this hypothesis in Tables D2D5. In Table D2, we run a similar analysis to that of Table D1, but with polynomials in the temperature deviation rather than the level of temperature. ${ }^{32}$ Similar to our findings in Table D1, we find significant non-linear effects in the size of the deviation for years of schooling, similarly-sized but statistically insignificant non-linearities for literacy, and no evidence of non-linearities for disability status. Tables D3-D5 also test for non-linearities in the size of the change in temperatures, but rather than fitting a polynomial uses nonparamettic indicator variables for a $+/$ - one standard deviation temperature shock and

\footnotetext{
${ }^{31}$ We stopped at the quartic term because higher order polynomial terms were insignificant.

${ }^{32}$ Similar to our analysis in Table D1, we stopped at cubic polynomials since higher order terms were insignificant.
} 
a $+/$ - two standard deviation temperature shock. We also test for positive (warmer) and negative (colder) shocks separately. Our results here are somewhat different from the results of the polynomial analysis of deviations. For years of schooling, we find no evidence of non-linearities in that the two standard deviation shocks are no larger than the one standard deviation shocks. In addition, we only find the expected effect for cool shocks rather than warm, and only for one standard deviation shocks. The literacy results, however, do exhibit evidence of non-linearities: warm shocks have a positive effect on literacy while cool shocks do not, and the effect of a two standard deviation warm shock is higher than a one standard deviation shock.

\section{Conclusion}

Using Census data for six sub-Saharan African countries, a combined dataset of DHS / MIS / AIS surveys for 31 sub-Saharan countries, and weather data from the University of Delaware, this paper shows that temperature extremes at the time of conception and early pregnancy are associated with better human capital outcomes later in life. Specifically, we find that educational attainment and literacy rise for individuals who were conceived during periods of elevated temperatures. We find no overall effect for changes in disabilities later in life in our full sample, but we do find decreases for men only.

To explain these findings, we explore a number of mechanisms that could underlie the relationship between temperature at conception and later life outcomes. We show that sexual activity falls during temperature spikes in the DHS / MIS / AIS data, as well as Google searches for sexually-themed words. However, we can only show mixed evidence that this selection actually occurs. Finally, when we control explicitly for parental characteristics of individuals whose parents live in the same household, we find that differences in these characteristics do not drive our results.

We then focus on the role of in utero selection. We show that known terminations are lower when temperature spikes occur in the months before a woman first reports being pregnant. We also find that the gender ratio of individuals born nine months after a 
temperature spike skew more female, indicative of intensified fetal loss. Finally, the effect of temperature on outcomes is significantly larger for males, also consistent with a fetal loss story.

This work contributes to the literature in several important ways. First, this is the first paper to analyze the effect of temperature before and just after birth on long-run human capital outcomes. Second, this is the first paper to focus on the effect at conception and test the unique behavioral and biological channels through which the conception effect may operate. We also contribute to the literature on temperature and fertility by demonstrating that periods of elevated temperatures are accompanied with increased fetal loss and declines in sexual activity. Finally, our work speaks to the Barker hypothesis which states that shocks in utero may have long lasting effects.

Our study also has implications for health, educational, and development policies in the developing world. Knowing that temperature at the time of conception and early pregnancy leads to fetal loss may cause policy makers to place a higher importance on programs which aim to reduce the negative effects of heat, such as increased electrification and the proliferation of air conditioning. This would be especially important for women trying to conceive and women who have just given birth.

Some have interpreted our findings as evidence that global warming is good for economic growth, since we find that higher temperatures lead to lower fertility and higher human capital. However, we take the opposite view. Our findings suggest these benefits come at a human cost of increased fetal loss. Miscarriage often comes with a high psychological and biological cost to parents, especially if these lost pregnancies were wanted. It also increases the probability that a couple will not be able to achieve their desired fertility. It is hard to imagine that such a tradeoff could be welfare maximizing. As a result, our study provides additional insight into the costs of global warming, which may raise the benefit of policies aimed at slowing climate change.

However, one must also be cautious when interpreting our results in relation to global warming. Since our identification comes from high-frequency deviations from tempera- 
ture means, it is entirely possible that as global temperatures rise, people will adapt. ${ }^{33}$ However, our findings suggest that full adaptation does not generally occur. For example, we find that in areas in which average temperatures are higher, the effect of a temperature shock is larger than in areas which are generally cooler. This suggests that increases in global temperatures will lead to more adverse health shocks to women and their unborn children, at least in the short run. The questions answered and raised by this paper inform key debates over the root causes of human capital formation - debates which are not only integral in determining correct policies aimed at reducing poverty in the developing world, but also strike at the very heart of the key questions asked by labor and development economists.

\footnotetext{
${ }^{33}$ Dell et al. (2014) provides a detailed discussion of the pitfalls of interpreting panel estimates of temperature on outcomes in the face of adaptation.
} 


\section{Acknowledgments}

We thank Tim-Allen Bruckner, Kasey Buckles, David Canning, Ken Chay, Isabelle Chort, Hippolyte D'Albis, Willa Friedman, Melanie Guldi, Giulia La Mattina, David Lam, Ron Lee, Mahesh Karra, Zoe McLaren, Joe Price, and David Weil, as well as participants in seminars at Brown University, Williams College, and the University of South Florida, the 7th Annual PopPov Research Conference, the XXVII IUSSP International Population Conference, the Pacific Conference for Development Economics, the European Society for Population Economics Conference, the Midwest International Development Conference, and the Rethinking Barker Essen Health Conference for helpful comments. We also thank a small army of research assistants: Walter Amoros, Joshua Barber, Joseph Coleman, David Doig, Meeka Etienne, David Frick, Stacey Gelsheimer, Emilia Gyoerk, Robyn Kibler, Corri Marteny, Richard McKenzie, Levon Mikaelian, Rebeccah Minix, Ale-

handro Roa, Suzana Santos, Dennis Skinner, Michael Stein, Tara Threewits, and Arseniy Yashkin. We also thank the support of Grant Number R03TW009108 from the Fogarty International Center. The content is the sole responsibility of the authors and does not necessarily represent the official views of the Fogarty International Center or the National Institutes of Health. 


\section{References}

Almond, Douglas, and Janet Currie. 2011. "Killing Me Softly: The Fetal Origins Hypothesis." Journal of Economic Perspectives, 25(3): 153-172.

Almond, D., and Bhashkar A. Mazumder. 2011. "Health Capital and the Prenatal Environment: The Effect of Ramadan Observance During Pregnancy." American Economic Journal: Applied Economics, 3(4): 56-85.

Barker, D. J. P., A. R. Bull, C. Osmond, and S. J. Simmonds. 1990. "Fetal and Placental Size and Risk of Hypertension in Adult Life." BMJ: British Medical Journal, 301(6746): 259-262.

Barreca, Alan I. 2012. "Climate Change, Humidity, and Mortality in the United States." Journal of Environmental Economics and Management, 63(1): 19-34.

Barreca, Alan, Oliver Deschênes, and Melanie Guldi. 2014. "It's Getting Hot in Here: The Effects of Ambient Temperature on Seasonal Birth Rates." Mimeo.

Barrios, Salvador, Luisito Bertinelli, and Eric Strobl. 2010. "Trends in Rainfall and Economic Growth in Africa: A Neglected Cause of the African Growth Tragedy." Review of Economics and Statistics, 92(2): 350-366.

Basu R., Malig B., Ostro B. 2010. "High ambient temperature and the risk of preterm delivery." American Journal of Epidemiology 172:1108-1117.

Bleakley, Hoyt. 2007. "Disease and Development: Evidence from Hookworm Eradication in the American South." The Quarterly Journal of Economics, 122(1): 73-117.

Boklage, Charles E. 1990. "Survival Probability of Human Conceptions from Fertilization to Term." International Journal of Fertility, 35(2): 75, 79-80, 81-94.

Brückner, Markus, and Antonio Ciccone. 2011. "Rain and the Democratic Window of Opportunity." Econometrica, 79(3): 923-947.

Buckles, Kasey S., and Daniel M. Hungerman. 2013. "Season of Birth and Later Outcomes: Old Questions, New Answers." Review of Economics and Statistics, 95(3): 711-724. 
Burgess, Robin, Olivier Deschênes, Dave Donaldson, and Michael Greenstone. 2011. "Weather and Death in India." Unpublished.

Catalano, Ralph, and Tim Bruckner. 2006. "Secondary Sex Ratios and Male Lifespan: Damaged or Culled Cohorts." Proceedings of the National Academy of Sciences of the United States of America, 103(5): 1639-1643.

Catalano, Ralph, Tim Bruckner, Elizabeth Anderson, and Jeffrey B. Gould. 2005. "Fetal death sex ratios: A test of the economic stress hypothesis." International Journal of Epidemiology, 34: 944-948.

Catalano, Ralph, Tim Bruckner, Amy Marks, and Brenda Eskenazi. 2006. "Exogenous shocks to the human sex ratio: The case of September 11th in New York City." Human Reproduction, 21(12):3127-31.

Chen, Yuyu, and Li-An Zhou. 2007. "The Long-Term Health and Economic Consequences of the 1959-1961 Famine in China." Journal of Health Economics, 26(4): 659-681.

Curriero, Frank C., Karlyn S. Heiner, Jonathan M. Samet, Scott L. Zeger, Lisa Strug, and Jonathan A. Patz. 2002. "Temperature and Mortality in 11 Cities of the Eastern United States." American Journal of Epidemiology, 157(1): 80-87.

Cutler, David M, Winnie Fung, Michael Kremer, Monica Singhal, and Tom Vogl. 2010. "Early Life Malaria Exposure and Adult Outcomes: Evidence from Malaria Eradication in India." American Economic Journal: Applied Economics, 2(2): 196-202.

Currie, Janet and Tom Vogl. 2013. "Early-Life Health and Adult Circumstance in Developing Countries." Annual Review of Economics, 5(1): 1-36.

Dell, Melissa, Benjamin Jones, and Benjamin Olken. 2012. "Temperature Shocks and Economic Growth: Evidence from the Last Half Century." American Economic Journal: Macroeconomics, 4(3): 66-95.

Dell, Melissa, Benjamin Jones, and Benjamin Olken. 2014. "What Do We Learn from the Weather? The New Climate-Economy Literature." Journal of Economic Literature, 52(3): $740-798$ 
Deryugina, Tatyana and Solomon M. Hsiang. "Does the Environment Still Matter? Daily Temperature and Income in the United States." NBER Working Paper No. 20750

Deschênes, Olivier, and Michael Greenstone. 2011. "Climate Change, Mortality, and Adaptation: Evidence from Annual Fluctuations in Weather in the US." American Economic Journal: Applied Economics, 3(4): 152-185.

Deschênes, Olivier, Michael Greenstone, and Jonathan Guryan. 2009. "Climate Change and Birth Weight." American Economic Review, 99(2): 211-217.

Gluckman, Peter D., Mark A. Hanson, Cyrus Cooper, and Kent L. Thornburg. 2008. "Effect of In Utero and Early-Life Conditions on Adult Health and Disease." New England Journal of Medicine, 359: 61-73.

Hernàndez-Juliàn, Rey, Hani Mansour, and Christina R. Peters. 2014. "The Effects of Intrauterine Malnutrition on Birth and Fertility Outcomes: Evidence from the 1974 Bangladesh Famine." Demography, 51(5): 1775-1796.

Holdaway, Taylor, Joshua Wilde, and Nicholas Wilson. 2016. "The Effects of Drought on NonAgricultural Output in the United States." University of South Florida Working Paper.

Hsiang, Solomon M. 2010. "Temperatures and cyclones strongly associated with economic production in the Caribbean and Central America." Proceedings of the National Academy of Sciences, 107(35): 15367-15372.

Isen, Adam, Maya Rossin-Slater, and Reed Walker. 2016. "Heat and Long-Run Human Capital Formation." Working Paper.

Kudamatsu, Masayuki, Torsten Persson, and David Stromberg. 2012. "Weather and Infant Mortality in Africa." Working Paper.

Lam, David, and Jeffrey A. Miron. 1991a. "Temperature and Seasonality of Births." In Temperature and Environmental Effects on the Testis, Advances in Experimental and Environmental Biology, ed. Adrian W. Zorgniotti, 286: 73-88. New York: Plenum Press. Lam, David, and Jeffrey A. Miron. 1991b. "Seasonality of Births in Human Populations." Social Biology, 38(1-2): 51-78. 
Lam, David, and Jeffrey A. Miron. 1994. "Global Patterns of Birth Seasonality in Human Populations." In Human Reproductive Ecology: Interactions of Environment, Fertility, and Behavior, Annals of the New York Academy of Sciences, eds. Kenneth L. Campbell and James W. Wood, 709: 9-28.

Lam, David, and Jeffrey A. Miron. 1996. "The Effect of Temperature on Human Fertility." Demography, 33(3): 291-305.

Lam, David, Jeffrey A. Miron, and Ann Riley. 1994. "Modeling Seasonality in Fecundability, Conceptions, and Births." Demography, 31(2): 321-346.

Liu, Elaine, Jin-Tan Liu, and Tzu-Yin Hazel Tseng. 2014. "The Effect of a Natural Disaster on the Incidence of Miscarriages, Stillbirths, and Pregnancy Outcomes." Mimeo.

Maccini, Sharon, and Dean Yang. 2009. "Under the Weather: Health, Schooling, and Economic Consequences of Early-Life Rainfall.” American Economic Review,, 99(3): 1006-1026

Markey, Patrick M., and Charlotte N. Markey. 2013. "Seasonal Variation in Internet Keyword Searches: A Proxy Assessment of Sex Mating Behaviors." Archives of Sexual Behavior, 42: $515-521$.

Minnesota Population Center. Integrated Public Use Microdata Series, International: Version 6.1 [Machine-readable database]. Minneapolis: University of Minnesota, 2014.

Nikolov, Plamen. 2012. "The Cognitive Link Between in Utero Nutrition and Development: Micronutrient Deficiency, Schooling Attainment, and Economic Outcomes in Tanzania." Mimeo.

Rominski, Sarah D., Mira Gupta, Raymond Aborigo, Phillip Adongo, Cyril Engman, Abraham Hodgson, and Cheryl Moyer. 2014. "Female Autonomy and Reported Abortion-Seeking in Ghana, West Africa." International Journal of Gynecology and Obstetrics, 126: 217-222.

Schlenker, Wolfram, and David B. Lobell. 2010. "Robust Negative Impacts of Climate Change on African Agriculture." Environmental Research Letters, 5(1): 014010

Seiver, Daniel A. 1985. "Trend and Variation in the Seasonality of US Fertility, 1947-1976." Demography, 22(1): 89-100. 
Seiver, Daniel A. 1989. "Seasonality of Fertility: New Evidence, 1947-1976." Population and Environment, 10(4): 245-257.

Wilcox, Allen J., Clarice R. Weinberg, John F. O’Connor, Donna D. Baird, John P. Schlatterer, Robert E. Canfield, E. Glenn Armstrong, and Bruce C. Nisula. 1988. Incidence of Early Loss of Pregnancy." New England Journal of Medicine, 319: 189-194.

Wilcox, Allen J., Donna Day Baird, and Clarice R. Weinberg. 1999. "Time of Implantation of the Conceptus and Loss of Pregnancy." New England Journal of Medicine, 340: 1796-1799.

Willmott, Cort J., and Kenji Matsuura. 2012. "Terrestrial Air Temperature: 1900-2010 Gridded Monthly Time Series (1900 - 2010) V 3.01.” http://climate.geog.udel.edu/ climate/html_pages/download.html\#T2011

Zivin, Joshua Graff, Solomon M. Hsiang, and Matthew Neidell. "Temperature and Human Capital in the Short- and Long-Run." NBER Working Paper No. 21157. 


\section{Tables}

Table I: Summary Statistics

\begin{tabular}{|c|c|c|}
\hline Variable & Mean & $\begin{array}{l}\text { Standard } \\
\text { Deviation }\end{array}$ \\
\hline
\end{tabular}

\section{Panel A. Weather Data}

Temperature at Conception $\left({ }^{\circ} \mathrm{C}\right) \quad 22.9 \quad 0.759$

$\begin{array}{lll}\text { Precipitation at Conception }(\mathrm{mm}) & 102.1 & 42.3\end{array}$

\section{Panel B. Census Data}

Years of Schooling - Imputed from Attainment $\quad 5.23 \quad 4.27$

$\begin{array}{lll}\text { Literacy } & 0.723 & 0.448\end{array}$

$\begin{array}{lll}\text { No Disability } & 0.972 & 0.165\end{array}$

Mother's Years of Schooling $\quad 3.36 \quad 4.11$

Father's Years of Schooling $\quad 5.16 \quad 4.70$

$\begin{array}{lll}\text { Female } & 0.507 & 0.500\end{array}$

\section{Panel C. DHS / MIS / AIS Data}

Death (Before age 12 Months)

$0.052 \quad 0.223$

Death (Between 12 and 24 Months)

$0.012 \quad 0.111$

Death (Between 24 and 36 Months)

$0.011 \quad 0.104$

Death (Between 36 and 48 Months)

$0.006 \quad 0.081$

Death (Between 48 and 60 Months)

$0.004 \quad 0.063$

Sexual Activity

$0.567 \quad 0.495$

Terminated Pregnancy

$0.078 \quad 0.268$

Mother's Primary Education +

$0.562 \quad 0.496$

Mother's Secondary Education $+\quad 0.176 \quad 0.381$

Improved Sanitation $\quad 0.264 \quad 0.440$

Improved Water

$0.578 \quad 0.493$ 
Table II: Temperature and Outcomes in the Census

\begin{tabular}{|c|c|c|c|c|c|c|}
\hline & $\begin{array}{c}(1) \\
\text { Years of } \\
\text { Schooling } \\
\text { (Attainment) }\end{array}$ & $\begin{array}{c}(2) \\
\text { Years of } \\
\text { Schooling } \\
\text { (Attainment) }\end{array}$ & $\begin{array}{c}(3) \\
\text { Literate } \\
\text { (Binary) }\end{array}$ & $\begin{array}{c}(4) \\
\text { Literate } \\
\text { (Binary) }\end{array}$ & $\begin{array}{c}(5) \\
\text { Not } \\
\text { Disabled } \\
\text { (Binary) }\end{array}$ & $\begin{array}{c}6) \\
\text { Not } \\
\text { Disabled } \\
\text { (Binary) }\end{array}$ \\
\hline Temperature at Birth - 15 & & $\begin{array}{c}0.0103 \\
(0.00896)\end{array}$ & & $\begin{array}{c}0.00161^{* *} \\
(0.000783)\end{array}$ & & $\begin{array}{l}-0.000143 \\
(0.000197)\end{array}$ \\
\hline Temperature at Birth - 14 & & $\begin{array}{c}0.0115 \\
(0.00756)\end{array}$ & & $\begin{array}{c}0.00168^{*} \\
(0.000882)\end{array}$ & & $\begin{array}{l}-0.000158 \\
(0.000179)\end{array}$ \\
\hline Temperature at Birth - 13 & & $\begin{array}{l}-0.00975 \\
(0.00665)\end{array}$ & & $\begin{array}{c}-9.44 \mathrm{e}-05 \\
(0.000590)\end{array}$ & & $\begin{array}{c}0.000345 \\
(0.000212)\end{array}$ \\
\hline Temperature at Birth - 12 & & $\begin{array}{c}0.00572 \\
(0.00884)\end{array}$ & & $\begin{array}{c}0.00178 * * * \\
(0.000609)\end{array}$ & & $\begin{array}{c}-3.79 \mathrm{e}-05 \\
(0.000179)\end{array}$ \\
\hline Temperature at Birth - 11 & & $\begin{array}{l}0.0149^{* *} \\
(0.00654)\end{array}$ & & $\begin{array}{r}0.00162^{* * *} \\
(0.000616)\end{array}$ & & $\begin{array}{l}-0.000201 \\
(0.000174)\end{array}$ \\
\hline Temperature at Birth - 10 & & $\begin{array}{c}0.00820 \\
(0.00678)\end{array}$ & & $\begin{array}{c}0.00115 \\
(0.000760)\end{array}$ & & $\begin{array}{r}-0.000410^{* *} \\
(0.000183)\end{array}$ \\
\hline Temperature at Birth - 9 & $\begin{array}{r}0.0317^{* *} \\
(0.0133)\end{array}$ & $\begin{array}{c}0.0158^{*} \\
(0.00838)\end{array}$ & $\begin{array}{c}0.00355 * * * \\
(0.00104)\end{array}$ & $\begin{array}{r}0.00204 * * * \\
(0.000777)\end{array}$ & $\begin{array}{l}-0.000224 \\
(0.000192)\end{array}$ & $\begin{array}{c}1.77 \mathrm{e}-05 \\
(0.000171)\end{array}$ \\
\hline Temperature at Birth -8 & & $\begin{array}{l}0.0256^{* *} \\
(0.0105)\end{array}$ & & $\begin{array}{r}0.00286^{* * *} \\
(0.000817)\end{array}$ & & $\begin{array}{l}-7.70 \mathrm{e}-05 \\
(0.000195)\end{array}$ \\
\hline Temperature at Birth -7 & & $\begin{array}{c}0.0193 * * * \\
(0.00635)\end{array}$ & & $\begin{array}{l}0.00148 * * \\
(0.000682)\end{array}$ & & $\begin{array}{c}-3.85 \mathrm{e}-05 \\
(0.000174)\end{array}$ \\
\hline Temperature at Birth - 6 & & $\begin{array}{c}0.0150^{*} \\
(0.00851)\end{array}$ & & $\begin{array}{r}0.00209 * * * \\
(0.000746)\end{array}$ & & $\begin{array}{l}-6.18 \mathrm{e}-05 \\
(0.000210)\end{array}$ \\
\hline Temperature at Birth -5 & & $\begin{array}{c}0.00461 \\
(0.00682)\end{array}$ & & $\begin{array}{c}0.00107^{*} \\
(0.000621)\end{array}$ & & $\begin{array}{c}-3.24 \mathrm{e}-05 \\
(0.000166)\end{array}$ \\
\hline Temperature at Birth - 4 & & $\begin{array}{c}0.00454 \\
(0.00653)\end{array}$ & & $\begin{array}{c}0.000768 \\
(0.000626)\end{array}$ & & $\begin{array}{c}0.000232 \\
(0.000192)\end{array}$ \\
\hline Temperature at Birth - 3 & & $\begin{array}{c}0.0119 \\
(0.00806)\end{array}$ & & $\begin{array}{c}0.00152^{* * *} \\
(0.000559)\end{array}$ & & $\begin{array}{c}-6.47 \mathrm{e}-05 \\
(0.000209)\end{array}$ \\
\hline Temperature at Birth - 2 & & $\begin{array}{c}0.0116^{*} \\
(0.00590)\end{array}$ & & $\begin{array}{c}0.00163 * * * \\
(0.000610)\end{array}$ & & $\begin{array}{l}-0.000229 \\
(0.000150)\end{array}$ \\
\hline Temperature at Birth - 1 & & $\begin{array}{r}-0.000973 \\
(0.00891)\end{array}$ & & $\begin{array}{c}0.000451 \\
(0.000918)\end{array}$ & & $\begin{array}{l}-0.000180 \\
(0.000193)\end{array}$ \\
\hline Temperature at Birth & & $\begin{array}{c}0.00595 \\
(0.00702)\end{array}$ & & $\begin{array}{c}0.00201 * * * \\
(0.000728)\end{array}$ & & $\begin{array}{c}0.000312 \\
(0.000201)\end{array}$ \\
\hline Temperature at Birth +1 & & $\begin{array}{c}0.00975 \\
(0.00876)\end{array}$ & & $\begin{array}{c}0.000519 \\
(0.000817)\end{array}$ & & $\begin{array}{l}-9.67 \mathrm{e}-05 \\
(0.000181)\end{array}$ \\
\hline Temperature at Birth +2 & & $\begin{array}{l}0.0167 * * \\
(0.00653)\end{array}$ & & $\begin{array}{c}0.00140^{*} \\
(0.000725)\end{array}$ & & $\begin{array}{c}0.000162 \\
(0.000160)\end{array}$ \\
\hline Temperature at Birth +3 & & $\begin{array}{c}0.00745 \\
(0.00733)\end{array}$ & & $\begin{array}{c}0.000658 \\
(0.000526)\end{array}$ & & $\begin{array}{l}-0.000212 \\
(0.000174)\end{array}$ \\
\hline Country-Year of Birth FE & Yes & Yes & Yes & Yes & Yes & Yes \\
\hline Region-Month of Birth FE & Yes & Yes & Yes & Yes & Yes & Yes \\
\hline Precipitation at Birth - 9 Only & Yes & No & Yes & No & Yes & No \\
\hline Full set of Precipitation Controls & No & Yes & No & Yes & No & Yes \\
\hline Observations & $3,475,680$ & $3,475,680$ & $3,475,680$ & $3,475,680$ & $3,475,680$ & $3,475,680$ \\
\hline R-squared & 0.256 & 0.256 & 0.174 & 0.174 & 0.014 & 0.014 \\
\hline
\end{tabular}

Notes: The variable "Temperature at Birth - X" refers to the temperature in Celsius degrees which prevails $\mathrm{X}$ months before birth. All regressions cluster at the region level. All regressions contain country-year fixed effects and region-month fixed effects. Standard errors are in parentheses. ${ }^{* * *} \mathrm{p}<0.01,{ }^{* *} \mathrm{p}<0.05$, ${ }^{*} \mathrm{p}<0.1$. 
Table III: Temperature and Child Mortality in the DHS / MIS / AIS

\begin{tabular}{|c|c|c|c|c|c|}
\hline & $\begin{array}{c}(1) \\
\text { Death } \\
0-12 \\
\text { months } \\
\end{array}$ & $\begin{array}{c}(2) \\
\text { Death } \\
12-24 \\
\text { months } \\
\end{array}$ & $\begin{array}{c}(3) \\
\text { Death } \\
24-36 \\
\text { months } \\
\end{array}$ & $\begin{array}{c}(4) \\
\text { Death } \\
36-48 \\
\text { months } \\
\end{array}$ & $\begin{array}{c}(5) \\
\text { Death } \\
48-60 \\
\text { months }\end{array}$ \\
\hline \multicolumn{6}{|l|}{ Panel A } \\
\hline Temperature at Birth - 9 & $\begin{array}{l}-0.0006 \\
(0.0017)\end{array}$ & $\begin{array}{c}0.0006 \\
(0.0010)\end{array}$ & $\begin{array}{l}-0.0006 \\
(0.0007)\end{array}$ & $\begin{array}{l}-0.0005 \\
(0.0004)\end{array}$ & $\begin{array}{c}0.0000 \\
(0.0004)\end{array}$ \\
\hline \multicolumn{6}{|l|}{ Panel B } \\
\hline Temperature at Birth - 15 & $\begin{array}{l}-0.0000 \\
(0.0018)\end{array}$ & $\begin{array}{c}-0.0000 \\
(0.0010)\end{array}$ & $\begin{array}{c}0.0004 \\
(0.0007)\end{array}$ & $\begin{array}{c}0.0001 \\
(0.0006)\end{array}$ & $\begin{array}{c}0.0001 \\
(0.0004)\end{array}$ \\
\hline Temperature at Birth - 14 & $\begin{array}{c}0.0029 \\
(0.0018)\end{array}$ & $\begin{array}{c}0.0004 \\
(0.0010)\end{array}$ & $\begin{array}{c}0.0007 \\
(0.0008)\end{array}$ & $\begin{array}{c}-0.0010^{*} \\
(0.0006)\end{array}$ & $\begin{array}{c}-0.0004 \\
(0.0004)\end{array}$ \\
\hline Temperature at Birth - 13 & $\begin{array}{c}0.0014 \\
(0.0018)\end{array}$ & $\begin{array}{c}0.0001 \\
(0.0009)\end{array}$ & $\begin{array}{c}-0.0008 \\
(0.0008)\end{array}$ & $\begin{array}{c}-0.0002 \\
(0.0006)\end{array}$ & $\begin{array}{c}0.0001 \\
(0.0004)\end{array}$ \\
\hline Temperature at Birth - 12 & $\begin{array}{c}0.0033^{*} \\
(0.0020)\end{array}$ & $\begin{array}{c}-0.0001 \\
(0.0010)\end{array}$ & $\begin{array}{c}0.0002 \\
(0.0007)\end{array}$ & $\begin{array}{c}-0.0009^{*} \\
(0.0005)\end{array}$ & $\begin{array}{c}-0.0002 \\
(0.0004)\end{array}$ \\
\hline Temperature at Birth - 11 & $\begin{array}{c}0.0009 \\
(0.0022)\end{array}$ & $\begin{array}{c}-0.0007 \\
(0.0011)\end{array}$ & $\begin{array}{c}0.0005 \\
(0.0007)\end{array}$ & $\begin{array}{c}0.0008 \\
(0.0006)\end{array}$ & $\begin{array}{c}-0.0010^{* * *} \\
(0.0004)\end{array}$ \\
\hline Temperature at Birth - 10 & $\begin{array}{c}-0.0019 \\
(0.0021)\end{array}$ & $\begin{array}{c}0.0004 \\
(0.0010)\end{array}$ & $\begin{array}{c}0.0004 \\
(0.0008)\end{array}$ & $\begin{array}{c}0.0004 \\
(0.0006)\end{array}$ & $\begin{array}{c}-0.0003 \\
(0.0004)\end{array}$ \\
\hline Temperature at Birth - 9 & $\begin{array}{c}-0.0022 \\
(0.0017)\end{array}$ & $\begin{array}{c}0.0005 \\
(0.0012)\end{array}$ & $\begin{array}{c}-0.0010 \\
(0.0008)\end{array}$ & $\begin{array}{c}-0.0008 \\
(0.0005)\end{array}$ & $\begin{array}{c}0.0003 \\
(0.0005)\end{array}$ \\
\hline Temperature at Birth -8 & $\begin{array}{l}-0.0009 \\
(0.0022)\end{array}$ & $\begin{array}{l}0.0011 \\
(0.0012)\end{array}$ & $\begin{array}{l}0.0017^{*} \\
(0.0009)\end{array}$ & $\begin{array}{l}0.0005 \\
(0.0005)\end{array}$ & $\begin{array}{l}-0.0002 \\
(0.0005)\end{array}$ \\
\hline Temperature at Birth - 7 & $\begin{array}{l}-0.0036^{*} \\
(0.0020)\end{array}$ & $\begin{array}{l}-0.0008 \\
(0.0009)\end{array}$ & $\begin{array}{l}-0.0009 \\
(0.0009)\end{array}$ & $\begin{array}{l}-0.0001 \\
(0.0006)\end{array}$ & $\begin{array}{c}0.0002 \\
(0.0005)\end{array}$ \\
\hline Temperature at Birth - 6 & $\begin{array}{c}0.0015 \\
(0.0018)\end{array}$ & $\begin{array}{c}-0.0011 \\
(0.0011)\end{array}$ & $\begin{array}{c}0.0013 \\
(0.0009)\end{array}$ & $\begin{array}{c}-0.0002 \\
(0.0006)\end{array}$ & $\begin{array}{c}0.0007^{*} \\
(0.0004)\end{array}$ \\
\hline Temperature at Birth - 5 & $\begin{array}{l}-0.0014 \\
(0.0020)\end{array}$ & $\begin{array}{l}0.0006 \\
(0.0010)\end{array}$ & $\begin{array}{l}-0.0004 \\
(0.0008)\end{array}$ & $\begin{array}{l}-0.0009 \\
(0.0005)\end{array}$ & $\begin{array}{c}0.0004 \\
(0.0004)\end{array}$ \\
\hline Temperature at Birth - 4 & $\begin{array}{l}-0.0001 \\
(0.0022)\end{array}$ & $\begin{array}{c}0.0004 \\
(0.0010)\end{array}$ & $\begin{array}{c}0.0015^{*} \\
(0.0009)\end{array}$ & $\begin{array}{c}-0.0008 \\
(0.0006)\end{array}$ & $\begin{array}{l}-0.0001 \\
(0.0005)\end{array}$ \\
\hline Temperature at Birth -3 & $\begin{array}{c}0.0013 \\
(0.0017)\end{array}$ & $\begin{array}{l}0.0005 \\
(0.0010)\end{array}$ & $\begin{array}{l}-0.0004 \\
(0.0009)\end{array}$ & $\begin{array}{l}0.0004 \\
(0.0005)\end{array}$ & $\begin{array}{l}-0.0002 \\
(0.0004)\end{array}$ \\
\hline Temperature at Birth - 2 & $\begin{array}{c}-0.0000 \\
(0.0018)\end{array}$ & $\begin{array}{c}0.0007 \\
(0.0009)\end{array}$ & $\begin{array}{c}-0.0003 \\
(0.0009)\end{array}$ & $\begin{array}{c}0.0004 \\
(0.0005)\end{array}$ & $\begin{array}{c}-0.0000 \\
(0.0005)\end{array}$ \\
\hline Temperature at Birth - 1 & $\begin{array}{l}0.0018 \\
(0.0021)\end{array}$ & $\begin{array}{c}0.0003 \\
(0.0009)\end{array}$ & $\begin{array}{c}0.0000 \\
(0.0009)\end{array}$ & $\begin{array}{l}-0.0004 \\
(0.0006)\end{array}$ & $\begin{array}{l}-0.0002 \\
(0.0005)\end{array}$ \\
\hline Temperature at Birth & $\begin{array}{l}-0.0013 \\
(0.0020)\end{array}$ & $\begin{array}{l}-0.0013 \\
(0.0011)\end{array}$ & $\begin{array}{c}0.0003 \\
(0.0008)\end{array}$ & $\begin{array}{l}-0.0004 \\
(0.0006)\end{array}$ & $\begin{array}{c}0.0004 \\
(0.0005)\end{array}$ \\
\hline Region-Month of Birth FE & Yes & Yes & Yes & Yes & Yes \\
\hline Country-Year of Birth FE & Yes & Yes & Yes & Yes & Yes \\
\hline Full Precipitation Controls & Yes & Yes & Yes & Yes & Yes \\
\hline Observations & 90,264 & 91,835 & 99,508 & 113,094 & 108,537 \\
\hline R-squared & 0.0547 & 0.0500 & 0.0466 & 0.0358 & 0.0365 \\
\hline
\end{tabular}

Notes: In column (1), the sample contains children who were born less than 12 months before the interview and the dependent variable is an indicator variable which takes a value of one if the child is dead at the time of the interview. In column (2), the sample contains children who were born 12 to 24 months before the interview and the dependent variable is an indicator variable which takes a value of one if the child died between ages 12 and 24 months. The sample and dependent variable in the following columns are defined accordingly. The variable "Temperature at Birth - X" refers to the temperature in Celsius degrees which prevails $\mathrm{X}$ months before birth. Standard errors, clustered at the region level, are in parentheses. ${ }^{* * *} \mathrm{p}<0.01,{ }^{* *} \mathrm{p}<0.05,{ }^{*} \mathrm{p}<0.1$. 
Table IV: Temperature and Sexual Activity in the DHS / MIS / AIS

\begin{tabular}{|c|c|c|c|c|c|}
\hline & $\begin{array}{c}(1) \\
\text { Sexually } \\
\text { Active }\end{array}$ & $\begin{array}{c}(2) \\
\text { Sexually } \\
\text { Active }\end{array}$ & $\begin{array}{c}(3) \\
\text { Sexually } \\
\text { Active }\end{array}$ & $\begin{array}{c}(4) \\
\text { Sexually } \\
\text { Active }\end{array}$ & $\begin{array}{c}(5) \\
\text { Sexually } \\
\text { Active }\end{array}$ \\
\hline Demeaned Temp at Interview - 2 & & $\begin{array}{c}0.0019 \\
(0.0023)\end{array}$ & $\begin{array}{c}0.0020 \\
(0.0023)\end{array}$ & $\begin{array}{c}0.0018 \\
(0.0023)\end{array}$ & $\begin{array}{c}0.0020 \\
(0.0023)\end{array}$ \\
\hline Demeaned Temp at Interview - 1 & & $\begin{array}{c}-0.0079 * * * \\
(0.0022)\end{array}$ & $\begin{array}{c}-0.0080 * * * \\
(0.0022)\end{array}$ & $\begin{array}{c}-0.0079 * * * \\
(0.0022)\end{array}$ & $\begin{array}{c}-0.0079 * * * \\
(0.0022)\end{array}$ \\
\hline Demeaned Temp at Interview & & $\begin{array}{l}-0.0021 \\
(0.0023)\end{array}$ & $\begin{array}{c}0.0016 \\
(0.0035)\end{array}$ & $\begin{array}{l}-0.0036 \\
(0.0024)\end{array}$ & $\begin{array}{l}-0.0021 \\
(0.0029)\end{array}$ \\
\hline Primary Edu + & $\begin{array}{c}-0.0154^{* * *} \\
(0.0046)\end{array}$ & & $\begin{array}{c}-0.0184^{* * *} \\
(0.0048)\end{array}$ & & \\
\hline Improved Sanitation & $\begin{array}{c}-0.0129 * * * \\
(0.0037)\end{array}$ & & & $\begin{array}{c}-0.0182^{* * *} \\
(0.0040)\end{array}$ & \\
\hline Improved Water & $\begin{array}{c}-0.0104^{* * *} \\
(0.0024)\end{array}$ & & & & $\begin{array}{c}-0.0141 * * * \\
(0.0027)\end{array}$ \\
\hline Demeaned Temp * Primary Edu + & & & $\begin{array}{l}-0.0052 \\
(0.0037)\end{array}$ & & \\
\hline Demeaned Temp * Improved Sanitation & & & & $\begin{array}{c}0.0054 \\
(0.0036)\end{array}$ & \\
\hline Demeaned Temp * Improved Water & & & & & $\begin{array}{c}0.0003 \\
(0.0028)\end{array}$ \\
\hline Region FE & Yes & Yes & Yes & Yes & Yes \\
\hline Month of Interview FE & Yes & Yes & Yes & Yes & Yes \\
\hline Year of Interview FE & Yes & Yes & Yes & Yes & Yes \\
\hline Woman's Age FE & Yes & Yes & Yes & Yes & Yes \\
\hline Observations & 443,976 & 443,976 & 443,976 & 443,976 & 443,976 \\
\hline R-squared & 0.1480 & 0.1476 & 0.1478 & 0.1478 & 0.1478 \\
\hline
\end{tabular}

Notes: The dependent variable is an indicator variable which takes the value one if the respondent was sexually active in the four weeks preceding the interview. "Demeaned Temperature at Interview - X" refers to the demeaned temperature in Celsius degrees prevailing in the respondent's region X months before the interview. The "Demeaned Temperature" variable in the interaction terms is the demeaned temperature at the time of the interview. Standard errors, clustered at the region level, are in parentheses. $* * * \mathrm{p}<0.01,{ }^{* *} \mathrm{p}<0.05,{ }^{*} \mathrm{p}<0.1$. 
Table V: Temperature and Google Searches in Africa

\begin{tabular}{|c|c|c|c|c|}
\hline & $\begin{array}{c}(1) \\
\text { Searches: } \\
\text { "Sex" }\end{array}$ & $\begin{array}{c}(2) \\
\text { Searches: } \\
\text { "Porn" }\end{array}$ & $\begin{array}{c}(3) \\
\text { Sexual Searches } \\
\text { Index }\end{array}$ & $\begin{array}{c}(4) \\
\text { Normalized } \\
\text { Index }\end{array}$ \\
\hline Temperature & $\begin{array}{c}-2.0525^{* *} \\
(1.0539)\end{array}$ & $\begin{array}{c}-3.0186^{*} \\
(1.6869)\end{array}$ & $\begin{array}{c}-2.3724^{* *} \\
(1.1255)\end{array}$ & $\begin{array}{c}-5.4691^{* * *} \\
(1.5345)\end{array}$ \\
\hline Internet Use & & & $\begin{array}{c}-0.2755^{* * *} \\
(0.0822)\end{array}$ & \\
\hline "Yahoo" & $\begin{array}{c}-0.1071^{* *} \\
(0.0489)\end{array}$ & $\begin{array}{l}-0.0184 \\
(0.0640)\end{array}$ & & \\
\hline "Google" & $\begin{array}{c}0.0060 \\
(0.0457)\end{array}$ & $\begin{array}{l}-0.1165 \\
(0.0779)\end{array}$ & & \\
\hline "Hotmail" & $\begin{array}{c}-0.1136^{* * *} \\
(0.0283)\end{array}$ & $\begin{array}{l}-0.0704 \\
(0.0451)\end{array}$ & & \\
\hline Region-Month FE & Yes & Yes & Yes & Yes \\
\hline Year FE & Yes & Yes & Yes & Yes \\
\hline Observations & 996 & 788 & 785 & 785 \\
\hline R-squared & 0.4368 & 0.6329 & 0.5934 & 0.5802 \\
\hline
\end{tabular}

Notes: The dependent variables are indexes of search frequency normalized to the mean level of searches during the sample period (2004-2010). The "Sexual Searches Index" is a composite index of searches of "sex" and "porn," while the "Normalized Index" is the sexual searches index divided by "Internet Use," a composite index of searches for the three control words "Yahoo", "Google," and "Hotmail." All regressions include year and region-month fixed effects. Robust standard errors are in parentheses. ${ }^{* * *} \mathrm{p}<0.01,{ }^{* *}$ $\mathrm{p}<0.05,{ }^{*} \mathrm{p}<0.1$. 
Table VI: Temperature and Parents' Characteristics in the DHS / MIS / AIS

\begin{tabular}{lcccc}
\hline & $\begin{array}{c}(1) \\
\text { Mother's } \\
\text { Primary } \\
\text { Edu }+\end{array}$ & $\begin{array}{c}\text { Mother's } \\
\text { Secondary } \\
\text { Edu }+\end{array}$ & $\begin{array}{c}(3) \\
\text { Improved } \\
\text { Sanitation }\end{array}$ & $\begin{array}{c}(4) \\
\text { Improved } \\
\text { Water }\end{array}$ \\
& 0.0023 & 0.0004 & $-0.0097^{* *}$ & -0.0030 \\
& $(0.0030)$ & $(0.0027)$ & $(0.0043)$ & $(0.0047)$ \\
Temperature at Birth - 9 & & & & \\
Region-Month of Birth FE & Yes & Yes & Yes & Yes \\
Country-Year of Birth FE & Yes & Yes & Yes & Yes \\
& & & & \\
Observations & 89,458 & 89,458 & 89,458 & 89,458 \\
R-squared & 0.4130 & 0.2682 & 0.3134 & 0.2039 \\
\hline
\end{tabular}

Notes: The sample contains mothers who gave birth in the year preceding the interview. "Mother's Primary +" indicates that the mother's level of education is at least primary. "Mother's Secondary +" indicates that the mother's level of education is at least secondary. Standard errors, clustered at the region level, are in parentheses. ${ }^{* * *} \mathrm{p}<0.01,{ }^{* *} \mathrm{p}<0.05,{ }^{*} \mathrm{p}<0.1$. 
Table VII: Temperature and Outcomes Controlling for Parents' Characteristics in the Census and in the DHS / MIS / AIS

\begin{tabular}{|c|c|c|c|c|c|c|c|c|}
\hline & $(1)$ & $(2)$ & $(3)$ & $(4)$ & $(5)$ & $(6)$ & $(7)$ & $(8)$ \\
\hline \multicolumn{9}{|l|}{ Panel A. Census } \\
\hline & $\begin{array}{l}\text { Years of } \\
\text { Schooling }\end{array}$ & $\begin{array}{l}\text { Years of } \\
\text { Schooling }\end{array}$ & Literate & Literate & $\begin{array}{c}\text { No } \\
\text { Disability }\end{array}$ & $\begin{array}{c}\text { No } \\
\text { Disability }\end{array}$ & & \\
\hline Temperature at Birth - 9 & $\begin{array}{c}0.00315 \\
(0.00826)\end{array}$ & $\begin{array}{c}-0.00148 \\
(0.00801)\end{array}$ & $\begin{array}{c}0.00108 \\
(0.000975)\end{array}$ & $\begin{array}{c}0.000673 \\
(0.000953)\end{array}$ & $\begin{array}{c}-0.000266 \\
(0.000299)\end{array}$ & $\begin{array}{l}-0.000270 \\
(0.000299)\end{array}$ & & \\
\hline Precipitation at Birth - 9 & $\begin{array}{c}5.53 \mathrm{e}-05 \\
(0.000194)\end{array}$ & $\begin{array}{c}4.94 \mathrm{e}-05 \\
(0.000187)\end{array}$ & $\begin{array}{l}-1.28 \mathrm{e}-06 \\
(1.86 \mathrm{e}-05)\end{array}$ & $\begin{array}{l}-1.62 \mathrm{e}-06 \\
(1.87 \mathrm{e}-05)\end{array}$ & $\begin{array}{l}-5.38 \mathrm{e}-06 \\
(4.11 \mathrm{e}-06)\end{array}$ & $\begin{array}{l}-5.46 \mathrm{e}-06 \\
(4.12 \mathrm{e}-06)\end{array}$ & & \\
\hline Mother's Education & & $0.132^{* * *}$ & & $0.0102^{* * *}$ & & $0.000291^{* * *}$ & & \\
\hline (Years) & & $(0.00325)$ & & $(0.000772)$ & & $(7.89 \mathrm{e}-05)$ & & \\
\hline Father's Education & & $0.160^{* * *}$ & & $0.0147^{* * *}$ & & $9.72 \mathrm{e}-05$ & & \\
\hline (Years) & & $(0.00646)$ & & $(0.00110)$ & & $(6.60 \mathrm{e}-05)$ & & \\
\hline Female & & $-0.102^{* *}$ & & $-0.0167^{* * *}$ & & $0.00269 * * *$ & & \\
\hline & & $(0.0467)$ & & $(0.00552)$ & & $(0.000435)$ & & \\
\hline Country-Year of Birth FE & Yes & Yes & Yes & Yes & Yes & Yes & & \\
\hline Region-Month of Birth FE & Yes & Yes & Yes & Yes & Yes & Yes & & \\
\hline Observations & 840,607 & 840,607 & 840,607 & 840,607 & 840,607 & 840,607 & & \\
\hline R-squared & 0.370 & 0.444 & 0.192 & 0.231 & 0.011 & 0.011 & & \\
\hline \multicolumn{9}{|l|}{ Panel B. DHS / MIS / AIS } \\
\hline & Death & Death & Death & Death & Death & Death & & \\
\hline Sample & $\begin{array}{l}0-12 \\
\text { months }\end{array}$ & $\begin{array}{c}0-12 \\
\text { months }\end{array}$ & $\begin{array}{l}0-12 \\
\text { months }\end{array}$ & $\begin{array}{l}0-12 \\
\text { months }\end{array}$ & $\begin{array}{l}0-12 \\
\text { months }\end{array}$ & $\begin{array}{c}0-12 \\
\text { months }\end{array}$ & & \\
\hline Temperature at Birth - 9 & -0.0021 & -0.0020 & -0.0021 & -0.0021 & -0.0021 & -0.0020 & & \\
\hline Mother's Primary Edu + & $(0.0017)$ & $\begin{array}{l}(0.0017) \\
-0.0029 \\
(0.0019)\end{array}$ & $(0.0017)$ & $(0.0017)$ & & $(0.0017)$ & & \\
\hline Mother's Secondary Edu + & & & $\begin{array}{c}-0.0066^{* * *} \\
(0.0024)\end{array}$ & & & $\begin{array}{c}-0.0066^{* * *} \\
(0.0024)\end{array}$ & & \\
\hline Improved Sanitation & & & & $\begin{array}{c}0.0000 \\
(0.0021)\end{array}$ & & $\begin{array}{c}0.0013 \\
(0.0021)\end{array}$ & & \\
\hline Improved Water & & & & & $\begin{array}{l}-0.0020 \\
(0.0019)\end{array}$ & $\begin{array}{l}-0.0015 \\
(0.0019)\end{array}$ & & \\
\hline Region-Month of Birth FE & Yes & Yes & Yes & Yes & Yes & Yes & & \\
\hline Country-Year of Birth FE & Yes & Yes & Yes & Yes & Yes & Yes & & \\
\hline Precipitation & Yes & Yes & Yes & Yes & & & & \\
\hline Observations & 89,458 & 89,458 & 89,458 & 89,458 & 89,458 & 89,458 & & \\
\hline R-squared & 0.0552 & 0.0552 & 0.0553 & 0.0552 & 0.0552 & 0.0553 & & \\
\hline
\end{tabular}

Notes: In Panel A, the dependent variables are defined the same as in the corresponding Tables II-IV. Parental education variables are measures in years of schooling imputed from attainment. In Panel B, the sample contains mothers who gave birth in year preceding the interview. "Mother's Primary Edu +" indicates that the mother's level of education is at least primary. "Mother's Secondary Edu +" indicates that the mother's level of education is at least secondary. In both panels, standard errors, clustered at the region-month of birth level, are in parentheses. ${ }^{* * *} \mathrm{p}<0.01,{ }^{* *} \mathrm{p}<0.05,{ }^{*} \mathrm{p}<0.1$. 
Table VIII: Temperature and Terminated Pregnancies in the DHS / MIS / AIS

\begin{tabular}{|c|c|c|c|c|}
\hline & $\begin{array}{c}(1) \\
\text { Termination }\end{array}$ & $\begin{array}{c}(2) \\
\text { Termination }\end{array}$ & $\begin{array}{c}(3) \\
\text { Termination }\end{array}$ & $\begin{array}{c}(4) \\
\text { Termination }\end{array}$ \\
\hline Temperature at MRP - 3 & & & $\begin{array}{r}-0.0041^{*} \\
(0.0025)\end{array}$ & $\begin{array}{l}-0.0040 \\
(0.0025)\end{array}$ \\
\hline Temperature at MRP - 2 & & & $\begin{array}{l}-0.0044^{*} \\
(0.0024)\end{array}$ & $\begin{array}{l}-0.0043^{*} \\
(0.0024)\end{array}$ \\
\hline Temperature at MRP - 1 & & $\begin{array}{c}-0.0060^{* *} \\
(0.0026)\end{array}$ & $\begin{array}{l}-0.0042 \\
(0.0026)\end{array}$ & $\begin{array}{l}-0.0041 \\
(0.0026)\end{array}$ \\
\hline Temperature at MRP & & & $\begin{array}{c}0.0012 \\
(0.0023)\end{array}$ & $\begin{array}{c}0.0013 \\
(0.0023)\end{array}$ \\
\hline Temperature at MRP +1 & & & $\begin{array}{l}-0.0003 \\
(0.0024)\end{array}$ & $\begin{array}{l}-0.0003 \\
(0.0024)\end{array}$ \\
\hline Mother's Primary Edu + & $\begin{array}{c}0.0109 * * * \\
(0.0031)\end{array}$ & & & $\begin{array}{c}0.0108^{* * *} \\
(0.0031)\end{array}$ \\
\hline Improved Sanitation & $\begin{array}{c}0.0099 * * * \\
(0.0025)\end{array}$ & & & $\begin{array}{c}0.0098^{* * *} \\
(0.0025)\end{array}$ \\
\hline Improved Water & $\begin{array}{c}0.0094^{* * *} \\
(0.0023)\end{array}$ & & & $\begin{array}{c}0.0093^{* * *} \\
(0.0023)\end{array}$ \\
\hline Year of Pregnancy FE & Yes & Yes & Yes & Yes \\
\hline Region-Month of Pregnancy FE & Yes & Yes & Yes & Yes \\
\hline Observations & 86,060 & 86,060 & 86,060 & 86,060 \\
\hline R-squared & 0.0591 & 0.0584 & 0.0586 & 0.0594 \\
\hline
\end{tabular}

Notes: The dependent variable is an indicator variable which takes the value of one if the woman reports that a pregnancy was terminated before birth for any reason. MRP is the first Month when the woman Reports being Pregnant. "Mother's Primary Edu +" indicates that the mother's level of education is at least primary. Standard errors, clustered by region, are in parentheses. ${ }^{* * *} \mathrm{p}<0.01,{ }^{*} \mathrm{p}<0.05,{ }^{*} \mathrm{p}<0.1$. 
Table IX: Temperature and Gender in the Census -2 and Under

\begin{tabular}{|c|c|c|}
\hline & $\begin{array}{c}(1) \\
\text { Female }\end{array}$ & $\begin{array}{c}(2) \\
\text { Female }\end{array}$ \\
\hline Temperature at Birth - 15 & & $\begin{array}{l}-0.00165 \\
(0.00128)\end{array}$ \\
\hline Temperature at Birth - 14 & & $\begin{array}{r}-0.000415 \\
(0.00115)\end{array}$ \\
\hline Temperature at Birth - 13 & & $\begin{array}{c}0.00209 \\
(0.00140)\end{array}$ \\
\hline Temperature at Birth - 12 & & $\begin{array}{r}-0.000827 \\
(0.00153)\end{array}$ \\
\hline Temperature at Birth - 11 & & $\begin{array}{l}-0.000120 \\
(0.00140)\end{array}$ \\
\hline Temperature at Birth - 10 & & $\begin{array}{l}-0.00177 \\
(0.00184)\end{array}$ \\
\hline Temperature at Birth - 9 & $\begin{array}{l}0.00249^{*} \\
(0.00132)\end{array}$ & $\begin{array}{c}0.00225^{* *} \\
(0.00108)\end{array}$ \\
\hline Temperature at Birth -8 & & $\begin{array}{c}0.00127 \\
(0.00102)\end{array}$ \\
\hline Temperature at Birth - 7 & & $\begin{array}{c}0.00102 \\
(0.00101)\end{array}$ \\
\hline Temperature at Birth - 6 & & $\begin{array}{c}-0.00243^{* *} \\
(0.00111)\end{array}$ \\
\hline Temperature at Birth -5 & & $\begin{array}{r}-0.000167 \\
(0.00126)\end{array}$ \\
\hline Temperature at Birth - 4 & & $\begin{array}{l}0.000858 \\
(0.00155)\end{array}$ \\
\hline Temperature at Birth - 3 & & $\begin{array}{c}0.00117 \\
(0.00144)\end{array}$ \\
\hline Temperature at Birth - 2 & & $\begin{array}{r}-0.000632 \\
(0.00132)\end{array}$ \\
\hline Temperature at Birth - 1 & & $\begin{array}{l}-0.000651 \\
(0.000999)\end{array}$ \\
\hline Temperature at Birth & & $\begin{array}{l}-0.000991 \\
(0.000978)\end{array}$ \\
\hline Temperature at Birth +1 & & $\begin{array}{c}0.00210 \\
(0.00129)\end{array}$ \\
\hline Temperature at Birth +2 & & $\begin{array}{l}0.000636 \\
(0.00131)\end{array}$ \\
\hline Temperature at Birth +3 & & $\begin{array}{l}0.000957 \\
(0.00107)\end{array}$ \\
\hline Country-Year of Birth FE & Yes & Yes \\
\hline Region-Month of Birth FE & Yes & Yes \\
\hline Precipitation at Birth - 9 Only & Yes & No \\
\hline Full set of Precipitation Controls & No & Yes \\
\hline Observations & 839,645 & 839,645 \\
\hline R-squared & 0.007 & 0.007 \\
\hline
\end{tabular}

Notes: The dependent variable is an indicator variable which takes a value of one if the individual is female. The sample is restricted to children who are less than two years old at the time of the interview. The variable "Temperature at Birth - X" refers to the temperature in Celsius degrees which prevails X months before birth. All regressions cluster at the region level. All regressions contain country-year fixed effects and region-month fixed effects. Standard errors are in parentheses. ${ }^{* * *} \mathrm{p}<0.01,{ }^{* *} \mathrm{p}<0.05$, ${ }^{*} \mathrm{p}<0.1$. 
Table X: Temperature and Outcomes by Gender in the Census

\begin{tabular}{lccc}
\hline & $\begin{array}{c}(1) \\
\text { Years of } \\
\text { Schooling } \\
\text { (Attainment) }\end{array}$ & $\begin{array}{c}(2) \\
\text { Literacy }\end{array}$ & $\begin{array}{c}\text { No } \\
\text { Disability }\end{array}$ \\
\hline Temperature at Birth - 9 & $0.131^{* * *}$ & $0.00995^{*}$ & $0.000558^{* *}$ \\
& $(0.0459)$ & $(0.00503)$ & $(0.000259)$ \\
Female & 0.368 & -0.0107 & $0.0170^{* * *}$ \\
& $(0.575)$ & $(0.0650)$ & $(0.00346)$ \\
Female * Temp. at Birth - 9 & $-0.0655^{* *}$ & $-0.00424^{* *}$ & $-0.000518^{* * *}$ \\
& $(0.0270)$ & $(0.00210)$ & $(0.000146)$ \\
Region-Month of Birth FE & Yes & Yes & Yes \\
Country-Year of Birth FE & Yes & Yes & Yes \\
Observations & & & \\
R-squared & $3,475,680$ & $3,475,680$ & $3,475,680$ \\
\hline
\end{tabular}

Notes: See Tables I-IV for descriptions of the dependent variables. The variable "Temperature at Birth - 9" refers to the temperature in Celsius degrees which prevails 9 months before birth. All regressions cluster at the region-month level. Standard errors are in parentheses. ${ }^{* * *} \mathrm{p}<0.01,{ }^{* *} \mathrm{p}<0.05,{ }^{*} \mathrm{p}<0.1$. 


\section{Appendix A: Evolution of Temperature Shocks over Time}

Table A: The Relationship between Temperature Levels and Temperature Deviations

\begin{tabular}{lccc}
\hline & $\begin{array}{c}(1) \\
\text { Temperature } \\
\text { Deviation }\end{array}$ & $\begin{array}{c}(2) \\
\text { Temperature } \\
\text { Deviation }\end{array}$ & $\begin{array}{c}(3) \\
\text { Temperature } \\
\text { Deviation }\end{array}$ \\
\hline Temperature & $\begin{array}{c}0.0851^{* * *} \\
(0.0091)\end{array}$ & & $0.0648^{* * *}$ \\
Year & & $0.00880^{* * *}$ & $\begin{array}{c}(0.0077) \\
\left(0.00762^{* * *}\right. \\
\text { Observations }\end{array}$ \\
R-squared & 94,428 & 94,428 & $(0.00033)$ \\
& 0.135 & 0.167 & 94,428 \\
\end{tabular}

Notes: Temperature Deviations refers to the absolute value of the distance between the actual temperature in a given region-month and the average temperature over all time in the region. The data used in the exercise are for all the countries in the Census sample. Robust standard errors are in parentheses. *** $\mathrm{p}<0.01,{ }^{* *} \mathrm{p}<0.05,{ }^{*} \mathrm{p}<0.1$

Figure A1: Distribution of Temperature Levels and Temperature Deviations

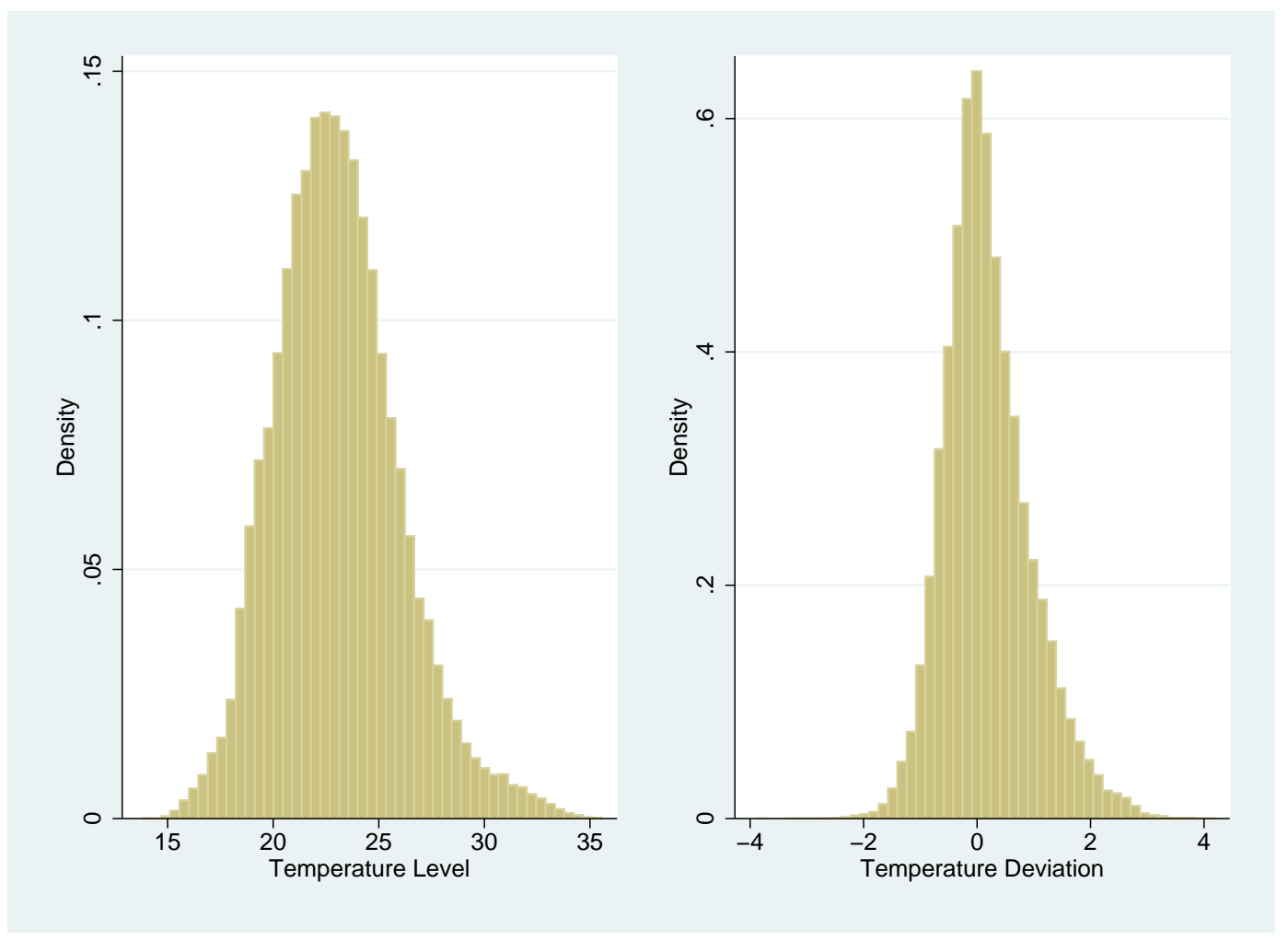

Notes: The data used in the exercise are for all the countries in the Census sample. 
Figure A2: Relationship between Temperature Deviations, Temperature Level in the Region, and Time
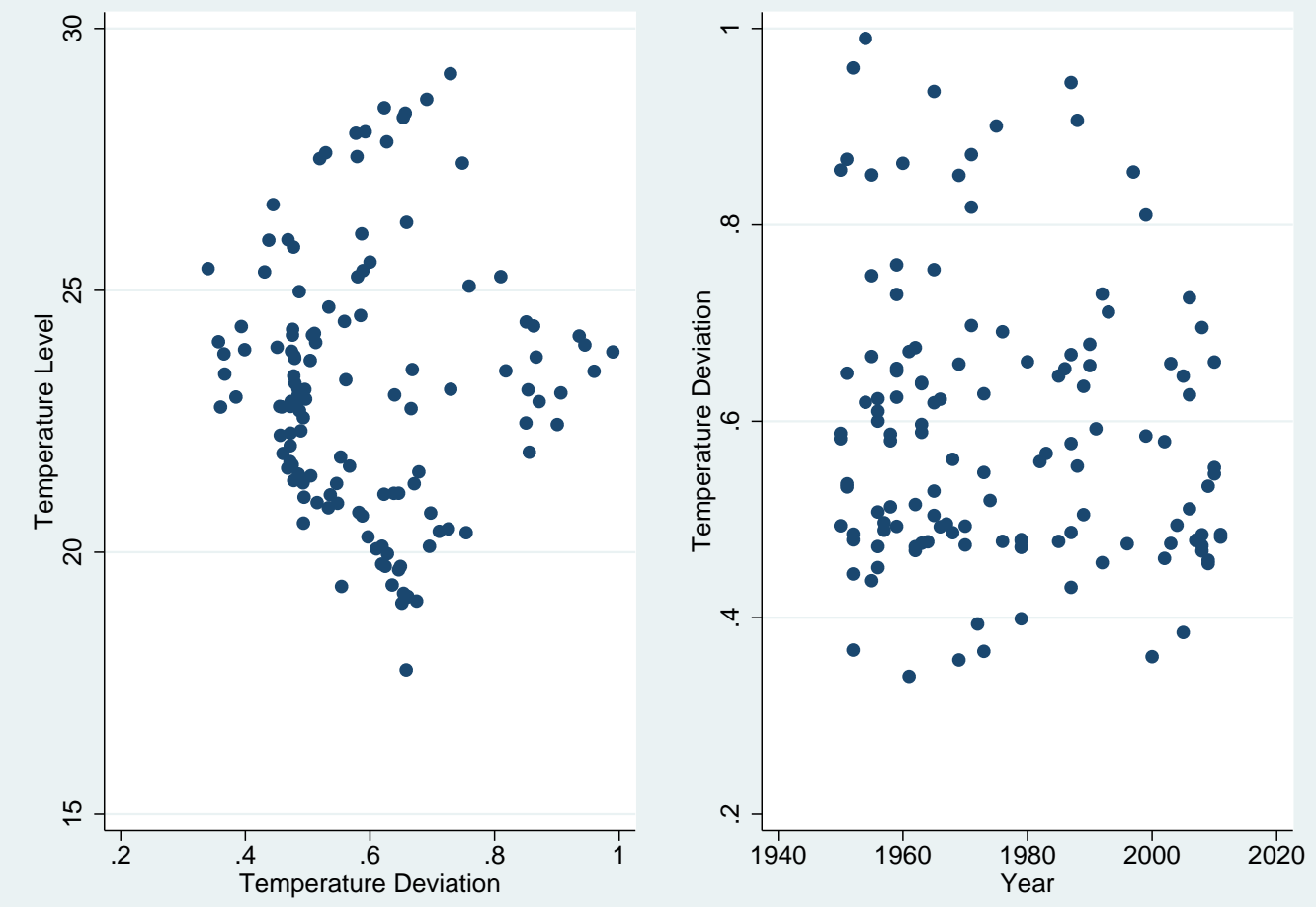

Notes: The data used in the exercise are for all the countries in the Census sample. 


\section{Appendix B: DHS Program Surveys}

Table B: List of Surveys in the DHS / MIS / AIS

\begin{tabular}{|c|c|c|c|}
\hline Country & Survey and Year & $\begin{array}{l}\text { Number } \\
\text { of regions }\end{array}$ & $\begin{array}{l}\text { Average region } \\
\text { area }\left(\mathrm{km}^{2}\right)\end{array}$ \\
\hline Angola & MIS/2006-07, MIS/2011 & 16 & 77,918 \\
\hline Benin & DHS/2001, DHS/2006, DHS/2011-12 & 6 & 18,770 \\
\hline Burkina Faso & DHS/2003, DHS / 2010 & 13 & 21,092 \\
\hline Burundi & DHS/2010, DHS / 2012 & 17 & 1,637 \\
\hline Cameroon & DHS/2004, DHS / 2011 & 9 & 52,826 \\
\hline Chad & DHS $/ 2004$ & 7 & 183,428 \\
\hline Comoros & DHS/2012 & 2 & 1,085 \\
\hline Congo Dem. Rep. & DHS/2007, DHS/2013-14 & 9 & 260,601 \\
\hline Côte d'Ivoire & AIS/2005, DHS/2011-12 & 9 & 35,829 \\
\hline Gabon & $\operatorname{DHS}(\mathrm{I}) / 2012$ & 9 & 29,740 \\
\hline Ghana & DHS $/ 2003$, DHS $/ 2008$ & 10 & 23,853 \\
\hline Guinea & DHS/2005, DHS/2012 & 4 & 61,464 \\
\hline Kenya & DHS/2003, DHS/2008-09 & 8 & 72,831 \\
\hline Lesotho & DHS/2004-05, DHS/2009-10 & 8 & 3,794 \\
\hline Liberia & $\begin{array}{l}\text { DHS/2006-07, MIS/2008-09, MIS/2011, } \\
\text { DHS/2013 }\end{array}$ & 12 & 9,280 \\
\hline Madagascar & $\begin{array}{l}\text { DHS / 2003-04, DHS/2008-09, MIS/2011, } \\
\text { MIS / } 2013\end{array}$ & 6 & 97,840 \\
\hline Malawi & $\begin{array}{l}\text { DHS / } 2000, \text { DHS } / 2004-05, \text { DHS } / 2010, \\
\text { MIS / } 2012, \text { DHS } / 2014\end{array}$ & 26 & 4,556 \\
\hline Mali & DHS / 2001, DHS/2006, DHS/2012-13 & 8 & 155,024 \\
\hline Mozambique & DHS/2003-04, DHS/2011 & 10 & 80,159 \\
\hline Namibia & DHS /2000, DHS / 2006-07, DHS / 2013 & 13 & 63,493 \\
\hline Niger & DHS/2006, DHS/2012 & 7 & 181,000 \\
\hline Nigeria & $\begin{array}{l}\text { DHS } / 2003, \text { DHS } / 2008, \text { MIS } / 2010, \\
\text { DHS } / 2013\end{array}$ & 37 & 24,966 \\
\hline Rwanda & $\begin{array}{l}\text { DHS } / 2000, \text { DHS } / 2005, \text { DHS(I) } / 2007-08, \\
\text { DHS } / 2010\end{array}$ & 10 & 2,633 \\
\hline Senegal & $\begin{array}{l}\text { DHS } / 2005, \text { MIS } / 2006, \text { MIS / 2008- } 09, \\
\text { DHS/2010-11, DHS/2012-13, DHS/2014 }\end{array}$ & 10 & 19,619 \\
\hline Sierra Leone & DHS/2008, DHS / 2013 & 4 & 17,935 \\
\hline Swaziland & DHS/2006-07 & 4 & 4,341 \\
\hline Tanzania & $\begin{array}{l}\text { DHS /2004-05, AIS/2007-08, DHS/2009-10, } \\
\text { AIS /2011-12 }\end{array}$ & 24 & 39,383 \\
\hline Togo & DHS $/ 2013-14$ & 5 & 11,357 \\
\hline Uganda & $\begin{array}{l}\text { DHS / 2000-01, DHS/2006, MIS/2009-10, } \\
\text { DHS/2011 }\end{array}$ & 4 & 60,259 \\
\hline Zambia & DHS /2001-02, DHS/2007, DHS/2013-14 & 9 & 83,623 \\
\hline Zimbabwe & DHS/2005-06, DHS/2010-11 & 10 & 39,058 \\
\hline Total & & 326 & \\
\hline
\end{tabular}

Notes: DHS stands for Demographic and Health Survey; DHS(I) for interim DHS; MIS for Malaria Indicator Survey; and AIS for AIDS Indicator Survey. In the last column, the average area of a region equals the area of the country divided by our number of regions. 


\section{Appendix C: The Effects of Temperature during the Dry and Rainy Seasons}

Table C1: Temperature and Outcomes in the Census - Rainy Season Only

\begin{tabular}{|c|c|c|c|c|c|c|}
\hline & $\begin{array}{c}(1) \\
\text { Years of } \\
\text { Schooling } \\
\text { (Attainment) }\end{array}$ & $\begin{array}{c}(2) \\
\text { Years of } \\
\text { Schooling } \\
\text { (Attainment) }\end{array}$ & $\begin{array}{c}(3) \\
\text { Literate } \\
\text { (Binary) }\end{array}$ & $\begin{array}{c}(4) \\
\text { Literate } \\
\text { (Binary) }\end{array}$ & $\begin{array}{c}(5) \\
\text { Not } \\
\text { Disabled } \\
\text { (Binary) }\end{array}$ & $\begin{array}{c}(6) \\
\text { Not } \\
\text { Disabled } \\
\text { (Binary) }\end{array}$ \\
\hline Temperature at Birth - 15 & & $\begin{array}{c}0.00429 \\
(0.00974)\end{array}$ & & $\begin{array}{c}0.000675 \\
(0.000902)\end{array}$ & & $\begin{array}{c}-0.000269 \\
(0.000248)\end{array}$ \\
\hline Temperature at Birth - 14 & & $\begin{array}{c}0.00237 \\
(0.0130)\end{array}$ & & $\begin{array}{c}0.00195 \\
(0.00146)\end{array}$ & & $\begin{array}{l}-0.000117 \\
(0.000234)\end{array}$ \\
\hline Temperature at Birth - 13 & & $\begin{array}{l}-0.00941 \\
(0.00673)\end{array}$ & & $\begin{array}{c}0.000719 \\
(0.000706)\end{array}$ & & $\begin{array}{c}0.000533^{*} \\
(0.000308)\end{array}$ \\
\hline Temperature at Birth - 12 & & $\begin{array}{c}-0.00818 \\
(0.0121)\end{array}$ & & $\begin{array}{c}0.000611 \\
(0.000691)\end{array}$ & & $\begin{array}{c}0.000341 \\
(0.000291)\end{array}$ \\
\hline Temperature at Birth - 11 & & $\begin{array}{c}0.0161^{*} \\
(0.00833)\end{array}$ & & $\begin{array}{c}0.00137^{*} \\
(0.000703)\end{array}$ & & $\begin{array}{c}-5.71 \mathrm{e}-05 \\
(0.000241)\end{array}$ \\
\hline Temperature at Birth - 10 & & $\begin{array}{c}0.0157 \\
(0.0116)\end{array}$ & & $\begin{array}{c}0.00264^{* *} \\
(0.00127)\end{array}$ & & $\begin{array}{c}-0.000829 * * \\
(0.000320)\end{array}$ \\
\hline Temperature at Birth - 9 & $\begin{array}{c}0.0527 * * * \\
(0.0187)\end{array}$ & $\begin{array}{c}0.0215^{*} \\
(0.0114)\end{array}$ & $\begin{array}{c}0.00431^{* * *} \\
(0.00145)\end{array}$ & $\begin{array}{l}0.00203 * * \\
(0.000942)\end{array}$ & $\begin{array}{c}-0.000451 \\
(0.000275)\end{array}$ & $\begin{array}{c}2.94 \mathrm{e}-05 \\
(0.000261)\end{array}$ \\
\hline Temperature at Birth - 8 & & $\begin{array}{c}0.0385^{* *} \\
(0.0156)\end{array}$ & & $\begin{array}{c}0.00391 * * * \\
(0.00135)\end{array}$ & & $\begin{array}{c}6.44 \mathrm{e}-05 \\
(0.000293)\end{array}$ \\
\hline Temperature at Birth - 7 & & $\begin{array}{c}0.0286 * * * \\
(0.00980)\end{array}$ & & $\begin{array}{c}0.000671 \\
(0.000911)\end{array}$ & & $\begin{array}{c}-0.000263 \\
(0.000340)\end{array}$ \\
\hline Temperature at Birth - 6 & & $\begin{array}{c}0.0219 \\
(0.0147)\end{array}$ & & $\begin{array}{l}0.00238^{*} \\
(0.00128)\end{array}$ & & $\begin{array}{c}0.000101 \\
(0.000349)\end{array}$ \\
\hline Temperature at Birth - 5 & & $\begin{array}{c}0.00106 \\
(0.0109)\end{array}$ & & $\begin{array}{c}0.00121 \\
(0.00100)\end{array}$ & & $\begin{array}{c}-2.59 \mathrm{e}-05 \\
(0.000270)\end{array}$ \\
\hline Temperature at Birth - 4 & & $\begin{array}{c}-0.00468 \\
(0.0123)\end{array}$ & & $\begin{array}{c}-0.000769 \\
(0.00123)\end{array}$ & & $\begin{array}{c}0.000146 \\
(0.000279)\end{array}$ \\
\hline Temperature at Birth - 3 & & $\begin{array}{c}0.0120 \\
(0.0110)\end{array}$ & & $\begin{array}{l}0.000487 \\
(0.00101)\end{array}$ & & $\begin{array}{l}-0.000131 \\
(0.000311)\end{array}$ \\
\hline Temperature at Birth - 2 & & $\begin{array}{c}0.0218^{* *} \\
(0.00945)\end{array}$ & & $\begin{array}{l}0.00219^{* *} \\
(0.000963)\end{array}$ & & $\begin{array}{l}-0.000123 \\
(0.000211)\end{array}$ \\
\hline Temperature at Birth - 1 & & $\begin{array}{l}-0.0150 \\
(0.0125)\end{array}$ & & $\begin{array}{c}0.000308 \\
(0.00134)\end{array}$ & & $\begin{array}{l}-0.000217 \\
(0.000296)\end{array}$ \\
\hline Temperature at Birth & & $\begin{array}{c}-0.0115 \\
(0.00969)\end{array}$ & & $\begin{array}{c}0.000995 \\
(0.000920)\end{array}$ & & $\begin{array}{c}0.000390 \\
(0.000323)\end{array}$ \\
\hline Temperature at Birth +1 & & $\begin{array}{l}0.00645 \\
(0.0103)\end{array}$ & & $\begin{array}{l}-0.000607 \\
(0.000954)\end{array}$ & & $\begin{array}{c}-0.000410^{*} \\
(0.000240)\end{array}$ \\
\hline Temperature at Birth +2 & & $\begin{array}{l}0.0210^{* *} \\
(0.00975)\end{array}$ & & $\begin{array}{l}0.00213^{* *} \\
(0.000981)\end{array}$ & & $\begin{array}{c}5.13 \mathrm{e}-05 \\
(0.000242)\end{array}$ \\
\hline Temperature at Birth +3 & & $\begin{array}{l}0.0108 \\
(0.0103)\end{array}$ & & $\begin{array}{c}0.00185^{* *} \\
(0.000772)\end{array}$ & & $\begin{array}{l}-0.000440^{*} \\
(0.000250)\end{array}$ \\
\hline Country-Year of Birth FE & Yes & Yes & Yes & Yes & Yes & Yes \\
\hline Region-Month of Birth FE & Yes & Yes & Yes & Yes & Yes & Yes \\
\hline Precipitation at Birth - 9 Only & Yes & No & Yes & No & Yes & No \\
\hline Full set of Precipitation Controls & No & Yes & No & Yes & No & Yes \\
\hline Observations & $1,731,541$ & $1,731,541$ & $1,731,541$ & $1,731,541$ & $1,731,541$ & $1,731,541$ \\
\hline R-squared & 0.275 & 0.275 & 0.178 & 0.178 & 0.014 & 0.015 \\
\hline
\end{tabular}

Notes: The variable "Temperature at Birth - X" refers to the temperature in Celsius degrees which prevails $\mathrm{X}$ months before birth. This table only keeps observations where the child was conceived (defined as nine months before birth) during a rainy season. All regressions cluster at the region level. All regressions contain country-year fixed effects and region-month fixed effects. Standard errors are in parentheses. ${ }^{* * *} \mathrm{p}<0.01,{ }^{* *} \mathrm{p}<0.05,{ }^{*} \mathrm{p}<0.1$. 
Table C2: Temperature and Outcomes in the Census - Dry Season Only

\begin{tabular}{|c|c|c|c|c|c|c|}
\hline & $\begin{array}{c}(1) \\
\text { Years of } \\
\text { Schooling } \\
\text { (Attainment) }\end{array}$ & $\begin{array}{c}(2) \\
\text { Years of } \\
\text { Schooling } \\
\text { (Attainment) }\end{array}$ & $\begin{array}{c}(3) \\
\text { Literate } \\
\text { (Binary) }\end{array}$ & $\begin{array}{c}(4) \\
\text { Literate } \\
\text { (Binary) }\end{array}$ & $\begin{array}{c}\text { Not } \\
\text { Not } \\
\text { Disabled } \\
\text { (Binary) }\end{array}$ & $\begin{array}{c}6) \\
\text { Not } \\
\text { Disabled } \\
\text { (Binary) }\end{array}$ \\
\hline Temperature at Birth - 15 & & $\begin{array}{c}0.0188 \\
(0.0123)\end{array}$ & & $\begin{array}{c}0.00266^{* *} \\
(0.00112)\end{array}$ & & $\begin{array}{l}-0.000107 \\
(0.000296)\end{array}$ \\
\hline Temperature at Birth - 14 & & $\begin{array}{c}0.0334^{* *} \\
(0.0148)\end{array}$ & & $\begin{array}{c}0.00214^{* *} \\
(0.000989)\end{array}$ & & $\begin{array}{l}-0.000287 \\
(0.000303)\end{array}$ \\
\hline Temperature at Birth - 13 & & $\begin{array}{l}0.00297 \\
(0.0127)\end{array}$ & & $\begin{array}{c}0.000244 \\
(0.000969)\end{array}$ & & $\begin{array}{c}0.000154 \\
(0.000276)\end{array}$ \\
\hline Temperature at Birth - 12 & & $\begin{array}{c}0.0122 \\
(0.0126)\end{array}$ & & $\begin{array}{c}0.00251^{* * *} \\
(0.000938)\end{array}$ & & $\begin{array}{l}-0.000271 \\
(0.000256)\end{array}$ \\
\hline Temperature at Birth - 11 & & $\begin{array}{c}0.00906 \\
(0.00973)\end{array}$ & & $\begin{array}{c}0.00148 \\
(0.000926)\end{array}$ & & $\begin{array}{l}-0.000332 \\
(0.000235)\end{array}$ \\
\hline Temperature at Birth - 10 & & $\begin{array}{r}-9.65 \mathrm{e}-05 \\
(0.00632)\end{array}$ & & $\begin{array}{c}-8.93 \mathrm{e}-05 \\
(0.000742)\end{array}$ & & $\begin{array}{l}-0.000170 \\
(0.000287)\end{array}$ \\
\hline Temperature at Birth - 9 & $\begin{array}{c}0.0150 \\
(0.0122)\end{array}$ & $\begin{array}{c}0.00776 \\
(0.00938)\end{array}$ & $\begin{array}{c}0.00286^{* * *} \\
(0.00107)\end{array}$ & $\begin{array}{c}0.00203 * * \\
(0.00102)\end{array}$ & $\begin{array}{c}-0.000125 \\
(0.000229)\end{array}$ & $\begin{array}{c}1.02 \mathrm{e}-05 \\
(0.000226)\end{array}$ \\
\hline Temperature at Birth -8 & & $\begin{array}{c}0.0107 \\
(0.0110)\end{array}$ & & $\begin{array}{r}0.00189 * * \\
(0.000851)\end{array}$ & & $\begin{array}{l}-0.000178 \\
(0.000253)\end{array}$ \\
\hline Temperature at Birth -7 & & $\begin{array}{c}0.0135 \\
(0.0114)\end{array}$ & & $\begin{array}{c}0.00190^{*} \\
(0.000971)\end{array}$ & & $\begin{array}{c}0.000222 \\
(0.000246)\end{array}$ \\
\hline Temperature at Birth - 6 & & $\begin{array}{c}0.00354 \\
(0.00795)\end{array}$ & & $\begin{array}{c}0.00170 * * \\
(0.000829)\end{array}$ & & $\begin{array}{c}-3.24 \mathrm{e}-05 \\
(0.000234)\end{array}$ \\
\hline Temperature at Birth -5 & & $\begin{array}{r}-0.00247 \\
(0.0105)\end{array}$ & & $\begin{array}{l}0.000784 \\
(0.00113)\end{array}$ & & $\begin{array}{l}-0.000176 \\
(0.000240)\end{array}$ \\
\hline Temperature at Birth - 4 & & $\begin{array}{c}0.00927 \\
(0.00876)\end{array}$ & & $\begin{array}{c}0.00271 * * * \\
(0.000898)\end{array}$ & & $\begin{array}{r}0.000260 \\
(0.000279)\end{array}$ \\
\hline Temperature at Birth -3 & & $\begin{array}{c}0.0146 \\
(0.00949)\end{array}$ & & $\begin{array}{c}0.00296 * * * \\
(0.000888)\end{array}$ & & $\begin{array}{c}-8.93 \mathrm{e}-05 \\
(0.000281)\end{array}$ \\
\hline Temperature at Birth - 2 & & $\begin{array}{c}0.00832 \\
(0.00984)\end{array}$ & & $\begin{array}{c}0.00146^{*} \\
(0.000806)\end{array}$ & & $\begin{array}{l}-0.000248 \\
(0.000260)\end{array}$ \\
\hline Temperature at Birth - 1 & & $\begin{array}{c}0.0241^{* *} \\
(0.0108)\end{array}$ & & $\begin{array}{c}0.00141 \\
(0.000916)\end{array}$ & & $\begin{array}{l}-0.000119 \\
(0.000300)\end{array}$ \\
\hline Temperature at Birth & & $\begin{array}{l}0.0190^{*} \\
(0.0108)\end{array}$ & & $\begin{array}{c}0.00285 * * \\
(0.00112)\end{array}$ & & $\begin{array}{r}0.000116 \\
(0.000302)\end{array}$ \\
\hline Temperature at Birth +1 & & $\begin{array}{l}0.00555 \\
(0.0103)\end{array}$ & & $\begin{array}{c}0.00149 \\
(0.00107)\end{array}$ & & $\begin{array}{r}0.000120 \\
(0.000245)\end{array}$ \\
\hline Temperature at Birth +2 & & $\begin{array}{c}0.0148^{*} \\
(0.00759)\end{array}$ & & $\begin{array}{c}0.000416 \\
(0.000929)\end{array}$ & & $\begin{array}{r}0.000293 \\
(0.000221)\end{array}$ \\
\hline Temperature at Birth +3 & & $\begin{array}{c}0.00806 \\
(0.00822)\end{array}$ & & $\begin{array}{c}-5.21 \mathrm{e}-05 \\
(0.000714)\end{array}$ & & $\begin{array}{l}-0.000157 \\
(0.000275)\end{array}$ \\
\hline Country-Year of Birth FE & Yes & Yes & Yes & Yes & Yes & Yes \\
\hline Region-Month of Birth FE & Yes & Yes & Yes & Yes & Yes & Yes \\
\hline Precipitation at Birth - 9 Only & Yes & No & Yes & No & Yes & No \\
\hline Full set of Precipitation Controls & No & Yes & No & Yes & No & Yes \\
\hline Observations & $1,744,139$ & $1,744,139$ & $1,744,139$ & $1,744,139$ & $1,744,139$ & $1,744,139$ \\
\hline R-squared & 0.237 & 0.237 & 0.171 & 0.171 & 0.014 & 0.014 \\
\hline
\end{tabular}

Notes: The variable "Temperature at Birth - X" refers to the temperature in Celsius degrees which prevails $\mathrm{X}$ months before birth. This table only keeps observations where the child was conceived (defined as nine months before birth) during a rainy season. All regressions cluster at the region level. All regressions contain country-year fixed effects and region-month fixed effects. Standard errors are in parentheses. ${ }^{* * *} \mathrm{p}<0.01,{ }^{* *} \mathrm{p}<0.05,{ }^{*} \mathrm{p}<0.1$. 
Table C3: Temperature and Outcomes in the Census - Interacted Model

\begin{tabular}{|c|c|c|c|c|c|c|}
\hline & $\begin{array}{c}(1) \\
\text { Years of } \\
\text { Schooling } \\
\text { (Attainment) }\end{array}$ & $\begin{array}{c}(2) \\
\text { Years of } \\
\text { Schooling } \\
\text { (Attainment) }\end{array}$ & $\begin{array}{c}(3) \\
\text { Literate } \\
\text { (Binary) }\end{array}$ & $\begin{array}{c}(4) \\
\text { Literate } \\
\text { (Binary) }\end{array}$ & $\begin{array}{c}\text { Not } \\
\text { Not } \\
\text { Disabled } \\
\text { (Binary) }\end{array}$ & $\begin{array}{c}\text { (6) } \\
\text { Not } \\
\text { Disabled } \\
\text { (Binary) }\end{array}$ \\
\hline Temperature at Birth - 15 & & $\begin{array}{c}0.0024 \\
(0.0102)\end{array}$ & & $\begin{array}{c}0.0006 \\
(0.0007)\end{array}$ & & $\begin{array}{c}0.0002 \\
(0.0002)\end{array}$ \\
\hline Temperature at Birth - 14 & & $\begin{array}{l}-0.0036 \\
(0.0115)\end{array}$ & & $\begin{array}{c}-0.0006 \\
(0.0012)\end{array}$ & & $\begin{array}{l}-0.0001 \\
(0.0002)\end{array}$ \\
\hline Temperature at Birth -13 & & $\begin{array}{c}-0.0266 * * * \\
(0.0092)\end{array}$ & & $\begin{array}{c}-0.0016^{* *} \\
(0.0007)\end{array}$ & & $\begin{array}{c}0.0003 \\
(0.0002)\end{array}$ \\
\hline Temperature at Birth - 12 & & $\begin{array}{l}-0.0051 \\
(0.0101)\end{array}$ & & $\begin{array}{l}6.38 \mathrm{e}-05 \\
(0.0007)\end{array}$ & & $\begin{array}{c}0.0001 \\
(0.0002)\end{array}$ \\
\hline Temperature at Birth - 11 & & $\begin{array}{l}-0.0055 \\
(0.0097)\end{array}$ & & $\begin{array}{l}-0.0007 \\
(0.0009)\end{array}$ & & $\begin{array}{l}-0.0002 \\
(0.0002)\end{array}$ \\
\hline Temperature at Birth - 10 & & $\begin{array}{l}-0.0087 \\
(0.0087)\end{array}$ & & $\begin{array}{l}-0.0005 \\
(0.0008)\end{array}$ & & $\begin{array}{l}-0.0002 \\
(0.0002)\end{array}$ \\
\hline Temperature at Birth - 9 & $\begin{array}{c}0.0264^{* *} \\
(0.0116)\end{array}$ & $\begin{array}{r}-0.0023 \\
(0.0092)\end{array}$ & $\begin{array}{c}0.0036^{* * *} \\
(0.0009)\end{array}$ & $\begin{array}{c}0.0008 \\
(0.0008)\end{array}$ & $\begin{array}{l}-0.0001 \\
(0.0002)\end{array}$ & $\begin{array}{l}0.0001 \\
(0.0001)\end{array}$ \\
\hline Temperature at Birth -8 & & $\begin{array}{l}0.0183^{*} \\
(0.0102)\end{array}$ & & $\begin{array}{l}0.0015^{*} \\
(0.0008)\end{array}$ & & $\begin{array}{l}-0.0001 \\
(0.0002)\end{array}$ \\
\hline Temperature at Birth - 7 & & $\begin{array}{c}0.0036 \\
(0.0097)\end{array}$ & & $\begin{array}{l}-0.0001 \\
(0.0008)\end{array}$ & & $\begin{array}{l}0.0001 \\
(0.0002)\end{array}$ \\
\hline Temperature at Birth - 6 & & $\begin{array}{l}-0.0035 \\
(0.0129)\end{array}$ & & $\begin{array}{c}0.0005 \\
(0.0012)\end{array}$ & & $\begin{array}{c}0.0001 \\
(0.0002)\end{array}$ \\
\hline Temperature at Birth - 5 & & $\begin{array}{c}-0.0262^{* *} \\
(0.0108)\end{array}$ & & $\begin{array}{l}-0.0016^{*} \\
(0.0008)\end{array}$ & & $\begin{array}{l}6.33 \mathrm{e}-05 \\
(0.0002)\end{array}$ \\
\hline Temperature at Birth - 4 & & $\begin{array}{c}-0.0216^{* *} \\
(0.0089)\end{array}$ & & $\begin{array}{l}-0.0016^{*} \\
(0.0008)\end{array}$ & & $\begin{array}{c}0.0003 \\
(0.0002)\end{array}$ \\
\hline Temperature at Birth -3 & & $\begin{array}{l}-0.0059 \\
(0.0110)\end{array}$ & & $\begin{array}{l}-0.0001 \\
(0.0010)\end{array}$ & & $\begin{array}{c}0.0001 \\
(0.0002)\end{array}$ \\
\hline Temperature at Birth - 2 & & $\begin{array}{l}-0.0130 \\
(0.0090)\end{array}$ & & $\begin{array}{l}-0.0004 \\
(0.0009)\end{array}$ & & $\begin{array}{l}-0.0001 \\
(0.0002)\end{array}$ \\
\hline Temperature at Birth - 1 & & $\begin{array}{l}-0.0090 \\
(0.0099)\end{array}$ & & $\begin{array}{l}-0.0004 \\
(0.0010)\end{array}$ & & $\begin{array}{l}9.94 \mathrm{e}-05 \\
(0.0002)\end{array}$ \\
\hline Temperature at Birth & & $\begin{array}{l}-0.0015 \\
(0.0084)\end{array}$ & & $\begin{array}{c}0.0011 \\
(0.0011)\end{array}$ & & $\begin{array}{l}0.0005^{* *} \\
(0.0002)\end{array}$ \\
\hline Temperature at Birth +1 & & $\begin{array}{c}0.0008 \\
(0.0097)\end{array}$ & & $\begin{array}{l}-0.0002 \\
(0.0009)\end{array}$ & & $\begin{array}{l}-7.72 \mathrm{e}-05 \\
(0.0002)\end{array}$ \\
\hline Temperature at Birth +2 & & $\begin{array}{l}0.0176^{* *} \\
(0.0082)\end{array}$ & & $\begin{array}{c}0.0012 \\
(0.0008)\end{array}$ & & $\begin{array}{l}0.0003 \\
(0.0001)\end{array}$ \\
\hline Temperature at Birth +3 & & $\begin{array}{c}0.0090 \\
(0.0075)\end{array}$ & & $\begin{array}{c}0.0003 \\
(0.0006)\end{array}$ & & $\begin{array}{c}-2.19 \mathrm{e}-05 \\
(0.0002)\end{array}$ \\
\hline Temperature at Birth $-15 *$ Rainy & & $\begin{array}{l}0.0238^{* *} \\
(0.0109)\end{array}$ & & $\begin{array}{c}0.0023^{* *} \\
(0.0011)\end{array}$ & & $-0.0004^{*}$ \\
\hline Temperature at Birth $-14 *$ Rainy & & $\begin{array}{l}0.0263^{* *} \\
(0.0128)\end{array}$ & & $\begin{array}{c}0.0038^{* * *} \\
(0.0012)\end{array}$ & & $\begin{array}{l}0.0001 \\
(0.0003)\end{array}$ \\
\hline Temperature at Birth $-13 *$ Rainy & & $\begin{array}{c}0.0367^{* * *} \\
(0.0139)\end{array}$ & & $\begin{array}{c}0.0028^{* *} \\
(0.0013)\end{array}$ & & $\begin{array}{l}-0.0003 \\
(0.0003)\end{array}$ \\
\hline Temperature at Birth $-12 *$ Rainy & & $\begin{array}{l}0.0246^{* *} \\
(0.0102)\end{array}$ & & $\begin{array}{c}0.0034^{* * *} \\
(0.0012)\end{array}$ & & $\begin{array}{l}-0.0005^{*} \\
(0.0003)\end{array}$ \\
\hline Temperature at Birth $-11 *$ Rainy & & $\begin{array}{c}0.0388^{* * *} \\
(0.0143)\end{array}$ & & $\begin{array}{c}0.0039 * * * \\
(0.0014)\end{array}$ & & $\begin{array}{l}6.18 \mathrm{e}-05 \\
(0.0003)\end{array}$ \\
\hline Temperature at Birth $-10 *$ Rainy & & $\begin{array}{l}0.0343^{* *} \\
(0.0138)\end{array}$ & & $\begin{array}{l}0.0030^{* *} \\
(0.0013)\end{array}$ & & $\begin{array}{l}-0.0002 \\
(0.0003)\end{array}$ \\
\hline Temperature at Birth - $9 *$ Rainy & $\begin{array}{c}0.0124 \\
(0.0117)\end{array}$ & $\begin{array}{c}0.0385^{* * *} \\
(0.0129)\end{array}$ & $\begin{array}{c}-0.0002 \\
(0.0010)\end{array}$ & $\begin{array}{c}0.0018 \\
(0.0012)\end{array}$ & $\begin{array}{l}-0.0002 \\
(0.0002)\end{array}$ & $\begin{array}{l}-0.0003 \\
(0.0002)\end{array}$ \\
\hline Temperature at Birth $-8 *$ Rainy & & $\begin{array}{c}0.0097 \\
(0.0171)\end{array}$ & & $\begin{array}{l}0.0029^{*} \\
(0.0017)\end{array}$ & & $\begin{array}{l}5.70 \mathrm{e}-05 \\
(0.0003)\end{array}$ \\
\hline Temperature at Birth $-7 *$ Rainy & & $\begin{array}{l}0.0312^{* *} \\
(0.0149)\end{array}$ & & $\begin{array}{l}0.0034^{* *} \\
(0.0013)\end{array}$ & & $\begin{array}{l}-0.0003 \\
(0.0003)\end{array}$ \\
\hline Temperature at Birth $-6 *$ Rainy & & $\begin{array}{l}0.0339^{* *} \\
(0.0162)\end{array}$ & & $\begin{array}{c}0.0029 \\
(0.0019)\end{array}$ & & $\begin{array}{l}-0.0003 \\
(0.0003)\end{array}$ \\
\hline Temperature at Birth $-5 *$ Rainy & & $\begin{array}{c}0.0568^{* * *} \\
(0.0171)\end{array}$ & & $\begin{array}{c}0.0051 * * * \\
(0.0015)\end{array}$ & & $\begin{array}{l}-0.0004 \\
(0.0003)\end{array}$ \\
\hline Temperature at Birth $-4 *$ Rainy & & $\begin{array}{c}0.0503^{* * *} \\
(0.0142)\end{array}$ & & $\begin{array}{c}0.0046^{* * *} \\
(0.0014)\end{array}$ & & $\begin{array}{l}-0.0003 \\
(0.0003)\end{array}$ \\
\hline Temperature at Birth $-3 *$ Rainy & & $\begin{array}{l}0.0349^{* *} \\
(0.0146)\end{array}$ & & $\begin{array}{c}0.0032^{*} \\
(0.0016)\end{array}$ & & $\begin{array}{l}-0.0004 \\
(0.0003)\end{array}$ \\
\hline Temperature at Birth $-2^{*}$ Rainy & & $\begin{array}{c}0.0526^{* * *} \\
(0.0121)\end{array}$ & & $\begin{array}{c}0.0043^{* * *} \\
(0.0014)\end{array}$ & & $\begin{array}{c}-7.46 \mathrm{e}-06 \\
(0.0003)\end{array}$ \\
\hline Temperature at Birth - $1 *$ Rainy & & $\begin{array}{c}0.0111 \\
(0.0117)\end{array}$ & & $\begin{array}{c}0.0016 \\
(0.0011)\end{array}$ & & $\begin{array}{l}-0.0004 \\
(0.0003)\end{array}$ \\
\hline Temperature at Birth* Rainy & & $\begin{array}{c}0.0133 \\
(0.0104)\end{array}$ & & $\begin{array}{c}0.0017 \\
(0.0014)\end{array}$ & & $\begin{array}{l}-0.0004 \\
(0.0003)\end{array}$ \\
\hline Temperature at Birth $+1 *$ Rainy & & $\begin{array}{l}0.0199^{* *} \\
(0.0099)\end{array}$ & & $\begin{array}{l}0.0021^{*} \\
(0.0011)\end{array}$ & & $\begin{array}{l}-0.0001 \\
(0.0003)\end{array}$ \\
\hline Temperature at Birth $+2 *$ Rainy & & $\begin{array}{c}0.0090 \\
(0.0102)\end{array}$ & & $\begin{array}{l}0.0015 \\
(0.0011)\end{array}$ & & $\begin{array}{l}-0.0003 \\
(0.0003)\end{array}$ \\
\hline Temperature at Birth $+3 *$ Rainy & & $\begin{array}{c}-0.0021 \\
(0.0104)\end{array}$ & & $\begin{array}{c}0.0009 \\
(0.0010)\end{array}$ & & $\begin{array}{c}-0.0003 \\
(0.0002)\end{array}$ \\
\hline Observations & $3,475,680$ & $3,475,680$ & $3,475,680$ & $3,475,680$ & $3,475,680$ & $3,475,680$ \\
\hline
\end{tabular}

Notes: The variable "Temperature at Birth - X" refers to the temperature in Celsius degrees which prevails X months before birth. All regressions cluster at the region level. All regressions contain country-year fixed effects, region-month fixed effects, and controls for rain in each month from 15 months before birth to 3 months after birth. Robust standard errors are in parentheses. ${ }^{* * *} \mathrm{p}<0.01,{ }^{* *} \mathrm{p}<0.05,{ }^{*} \mathrm{p}<0.1$. 
Figure C: Temperature and Gender: Heterogeneity by Season

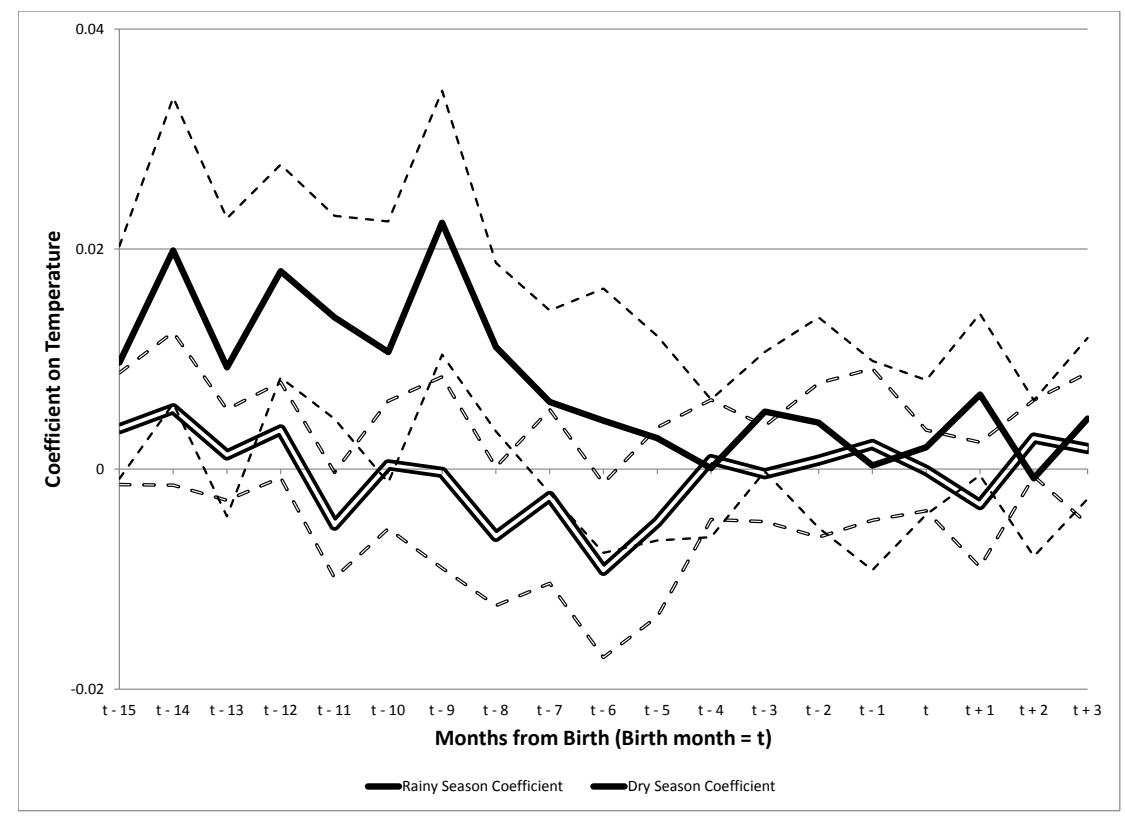


Table C4: Temperature and Gender in the Census - Interacted Model

\begin{tabular}{|c|c|c|}
\hline VARIABLES & $\begin{array}{l}(1) \\
\text { sex }\end{array}$ & $\begin{array}{l}(2) \\
\text { sex }\end{array}$ \\
\hline Temperature at Birth - 15 & & $\begin{array}{c}0.00366 \\
(0.00257)\end{array}$ \\
\hline Temperature at Birth - 14 & & $\begin{array}{c}0.00549 \\
(0.00352)\end{array}$ \\
\hline Temperature at Birth - 13 & & $\begin{array}{c}0.00129 \\
(0.00209)\end{array}$ \\
\hline Temperature at Birth - 12 & & $\begin{array}{c}0.00356 \\
(0.00219)\end{array}$ \\
\hline Temperature at Birth - 11 & & $\begin{array}{c}-0.00509^{* *} \\
(0.00242)\end{array}$ \\
\hline Temperature at Birth - 10 & & $\begin{array}{r}0.000390 \\
(0.00293)\end{array}$ \\
\hline Temperature at Birth - 9 & $\begin{array}{c}0.00362 \\
(0.00294)\end{array}$ & $\begin{array}{r}-0.000304 \\
(0.00439)\end{array}$ \\
\hline Temperature at Birth -8 & & $\begin{array}{r}-0.00612^{*} \\
(0.00318)\end{array}$ \\
\hline Temperature at Birth - 7 & & $\begin{array}{l}-0.00249 \\
(0.00399)\end{array}$ \\
\hline Temperature at Birth -6 & & $\begin{array}{c}-0.00921^{* *} \\
(0.00400)\end{array}$ \\
\hline Temperature at Birth - 5 & & $\begin{array}{c}-0.00482 \\
(0.00435)\end{array}$ \\
\hline Temperature at Birth - 4 & & $\begin{array}{l}0.000855 \\
(0.00275)\end{array}$ \\
\hline Temperature at Birth -3 & & $\begin{array}{r}-0.000431 \\
(0.00220)\end{array}$ \\
\hline Temperature at Birth - 2 & & $\begin{array}{r}0.000809 \\
(0.00354)\end{array}$ \\
\hline Temperature at Birth - 1 & & $\begin{array}{c}0.00224 \\
(0.00348)\end{array}$ \\
\hline Temperature at Birth & & $\begin{array}{r}-0.000131 \\
(0.00185)\end{array}$ \\
\hline Temperature at Birth +1 & & $\begin{array}{l}-0.00323 \\
(0.00286)\end{array}$ \\
\hline Temperature at Birth +2 & & $\begin{array}{c}0.00281 \\
(0.00175)\end{array}$ \\
\hline Temperature at Birth +3 & & $\begin{array}{c}0.00188 \\
(0.00346)\end{array}$ \\
\hline Temperature at Birth - $15 *$ Rainy & & $\begin{array}{c}0.00602 \\
(0.00481)\end{array}$ \\
\hline Temperature at Birth - $14 *$ Rainy & & $\begin{array}{c}0.0144^{*} \\
(0.00845)\end{array}$ \\
\hline Temperature at Birth $-13 *$ Rainy & & $\begin{array}{c}0.00796 \\
(0.00778)\end{array}$ \\
\hline Temperature at Birth $-12 *$ Rainy & & $\begin{array}{r}0.0144^{* * *} \\
(0.00516)\end{array}$ \\
\hline Temperature at Birth - $11 *$ Rainy & & $\begin{array}{r}0.0189^{* * *} \\
(0.00603)\end{array}$ \\
\hline Temperature at Birth $-10 *$ Rainy & & $\begin{array}{c}0.0102 \\
(0.00793)\end{array}$ \\
\hline Temperature at Birth - $9 *$ Rainy & $\begin{array}{l}0.0201 * * * \\
(0.00612)\end{array}$ & $\begin{array}{l}0.0227^{* *} \\
(0.00969)\end{array}$ \\
\hline Temperature at Birth $-8 *$ Rainy & & $\begin{array}{c}0.0172 * * * \\
(0.00602)\end{array}$ \\
\hline Temperature at Birth $-7 *$ Rainy & & $\begin{array}{c}0.00860 \\
(0.00621)\end{array}$ \\
\hline Temperature at Birth - $6 *$ Rainy & & $\begin{array}{r}0.0136^{* * *} \\
(0.00478)\end{array}$ \\
\hline Temperature at Birth $-5 *$ Rainy & & $\begin{array}{c}0.00201 \\
(0.00718)\end{array}$ \\
\hline Temperature at Birth - $4 *$ Rainy & & $\begin{array}{r}-0.000784 \\
(0.00363)\end{array}$ \\
\hline Temperature at Birth $-3 *$ Rainy & & $\begin{array}{c}-0.00479 \\
(0.00320)\end{array}$ \\
\hline Temperature at Birth $-2 *$ Rainy & & $\begin{array}{c}0.00341 \\
(0.00732)\end{array}$ \\
\hline Temperature at Birth $-1 *$ Rainy & & $\begin{array}{l}-0.00256 \\
(0.00738)\end{array}$ \\
\hline Temperature at Birth * Rainy & & $\begin{array}{c}0.00212 \\
(0.00346)\end{array}$ \\
\hline Temperature at Birth $+1 *$ Rainy & & $\begin{array}{l}0.0100^{* *} \\
(0.00430)\end{array}$ \\
\hline Temperature at Birth $+2 *$ Rainy & & $\begin{array}{l}-0.00364 \\
(0.00367)\end{array}$ \\
\hline Temperature at Birth $+3 *$ Rainy & & $\begin{array}{l}-0.00647 \\
(0.00445)\end{array}$ \\
\hline Country-Year of Birth FE & Yes & Yes \\
\hline Region-Month of Birth FE & Yes & Yes \\
\hline Precipitation at Birth - 9 Only & Yes & No \\
\hline Full set of Precipitation Controls & No & Yes \\
\hline Observations & 839,645 & 839,645 \\
\hline R-squared & 0.064 & 0.065 \\
\hline
\end{tabular}

Notes: The dependent variable is an indicator variable which takes a value of one if the individual is female. The sample is restricted to children who are less than two years old at the time of the interview. The variable "Temperature at Birth - X" refers to the temperature in Celsius degrees which prevails X months before birth. All regressions cluster at the region level. All regressions contain country-year fixed effects and region-month fixed effects. Standard errors are in parentheses. ${ }^{* * *} \mathrm{p}<0.01,{ }^{* *} \mathrm{p}<0.05$, ${ }^{*} \mathrm{p}<0.1$. 
Table C5: Temperature and Mortality During the Dry and Rainy Seasons in the DHS / MIS / AIS

\begin{tabular}{|c|c|c|c|c|}
\hline Season & $\begin{array}{c}(1) \\
\text { Death } \\
0-12 \\
\text { months } \\
\text { Dry season }\end{array}$ & $\begin{array}{c}(2) \\
\text { Death } \\
0-12 \\
\text { months } \\
\text { Dry season }\end{array}$ & $\begin{array}{c}(3) \\
\text { Death } \\
0-12 \\
\text { months } \\
\text { Rainy Season }\end{array}$ & $\begin{array}{c}(4) \\
\text { Death } \\
0-12 \\
\text { months } \\
\text { Rainy Season }\end{array}$ \\
\hline Temperature at Birth - 15 & & $\begin{array}{c}-0.0009 \\
(0.0039)\end{array}$ & & $\begin{array}{c}0.0008 \\
(0.0025)\end{array}$ \\
\hline Temperature at Birth - 14 & & $\begin{array}{c}0.0042 \\
(0.0032)\end{array}$ & & $\begin{array}{c}0.0005 \\
(0.0025)\end{array}$ \\
\hline Temperature at Birth - 13 & & $\begin{array}{l}-0.0014 \\
(0.0030)\end{array}$ & & $\begin{array}{c}0.0010 \\
(0.0029)\end{array}$ \\
\hline Temperature at Birth - 12 & & $\begin{array}{c}0.0016 \\
(0.0027)\end{array}$ & & $\begin{array}{c}0.0067^{* *} \\
(0.0028)\end{array}$ \\
\hline Temperature at Birth - 11 & & $\begin{array}{c}0.0026 \\
(0.0030)\end{array}$ & & $\begin{array}{c}0.0003 \\
(0.0033)\end{array}$ \\
\hline Temperature at Birth - 10 & & $\begin{array}{c}-0.0010 \\
(0.0026)\end{array}$ & & $\begin{array}{l}-0.0041 \\
(0.0034)\end{array}$ \\
\hline Temperature at Birth - 9 & $\begin{array}{c}-0.0030 \\
(0.0022)\end{array}$ & $\begin{array}{c}-0.0029 \\
(0.0023)\end{array}$ & $\begin{array}{c}-0.0019 \\
(0.0028)\end{array}$ & $\begin{array}{l}-0.0007 \\
(0.0034)\end{array}$ \\
\hline Temperature at Birth - 8 & & $\begin{array}{c}-0.0006 \\
(0.0030)\end{array}$ & & $\begin{array}{c}0.0004 \\
(0.0034)\end{array}$ \\
\hline Temperature at Birth - 7 & & $\begin{array}{c}-0.0027 \\
(0.0029)\end{array}$ & & $\begin{array}{l}-0.0042 \\
(0.0028)\end{array}$ \\
\hline Temperature at Birth - 6 & & $\begin{array}{l}0.0045^{*} \\
(0.0027)\end{array}$ & & $\begin{array}{l}-0.0008 \\
(0.0029)\end{array}$ \\
\hline Temperature at Birth - 5 & & $\begin{array}{c}-0.0008 \\
(0.0033)\end{array}$ & & $\begin{array}{l}-0.0015 \\
(0.0030)\end{array}$ \\
\hline Temperature at Birth - 4 & & $\begin{array}{c}-0.0029 \\
(0.0035)\end{array}$ & & $\begin{array}{c}0.0016 \\
(0.0028)\end{array}$ \\
\hline Temperature at Birth - 3 & & $\begin{array}{c}0.0011 \\
(0.0034)\end{array}$ & & $\begin{array}{c}0.0016 \\
(0.0026)\end{array}$ \\
\hline Temperature at Birth - 2 & & $\begin{array}{c}-0.0051 \\
(0.0031)\end{array}$ & & $\begin{array}{c}0.0027 \\
(0.0027)\end{array}$ \\
\hline Temperature at Birth - 1 & & $\begin{array}{c}0.0029 \\
(0.0036)\end{array}$ & & $\begin{array}{c}0.0023 \\
(0.0029)\end{array}$ \\
\hline Temperature at Birth & & $\begin{array}{l}-0.0002 \\
(0.0029)\end{array}$ & & $\begin{array}{l}-0.0024 \\
(0.0030)\end{array}$ \\
\hline Region-Month of Birth FE & Yes & Yes & Yes & Yes \\
\hline Country-Year of Birth FE & Yes & Yes & Yes & Yes \\
\hline Precipitation & Yes & Yes & Yes & Yes \\
\hline Observations & 45,218 & 45,218 & 45,046 & 45,046 \\
\hline R-squared & 0.0550 & 0.0554 & 0.0551 & 0.0557 \\
\hline
\end{tabular}

Notes: The sample contains children who were born less than 12 months before the interview and the dependent variable is an indicator variable which takes a value of one if the child is dead at the time of the interview. The variable "Temperature at Birth - X" refers to the temperature in Celsius degrees which prevails X months before birth. Standard errors, clustered at the region level, are in parentheses. $* * * \mathrm{p}<0.01,{ }^{* *} \mathrm{p}<0.05,{ }^{*} \mathrm{p}<0.1$. 
Table C6: Temperature and Sexual Activity During the Dry and Rainy Seasons in the DHS / MIS / AIS

\begin{tabular}{|c|c|c|c|c|}
\hline & $\begin{array}{c}(1) \\
\text { Sexually } \\
\text { Active } \\
\text { Dry Season }\end{array}$ & $\begin{array}{c}(2) \\
\text { Sexually } \\
\text { Active } \\
\text { Dry Season }\end{array}$ & $\begin{array}{c}(3) \\
\text { Sexually } \\
\text { Active } \\
\text { Rainy Season }\end{array}$ & $\begin{array}{c}\text { (4) } \\
\text { Sexually } \\
\text { Active } \\
\text { Rainy Season }\end{array}$ \\
\hline Demeaned Temp at Interview - 2 & $\begin{array}{c}-0.0003 \\
(0.0039)\end{array}$ & $\begin{array}{l}-0.0002 \\
(0.0038)\end{array}$ & $\begin{array}{c}0.0059 * \\
(0.0031)\end{array}$ & $\begin{array}{c}0.0062 * * \\
(0.0031)\end{array}$ \\
\hline Demeaned Temp at Interview - 1 & $\begin{array}{c}-0.0101^{* *} \\
(0.0040)\end{array}$ & $\begin{array}{c}-0.0101^{* *} \\
(0.0040)\end{array}$ & $\begin{array}{c}-0.0082^{* * *} \\
(0.0031)\end{array}$ & $\begin{array}{c}-0.0082^{* *} \\
(0.0032)\end{array}$ \\
\hline Demeaned Temp at Interview & $\begin{array}{l}-0.0055 \\
(0.0040)\end{array}$ & $\begin{array}{l}-0.0054 \\
(0.0039)\end{array}$ & $\begin{array}{c}0.0004 \\
(0.0029)\end{array}$ & $\begin{array}{c}0.0007 \\
(0.0029)\end{array}$ \\
\hline Primary Edu + & & $\begin{array}{l}-0.0083 \\
(0.0060)\end{array}$ & & $\begin{array}{c}-0.0188^{* * *} \\
(0.0053)\end{array}$ \\
\hline Improved Sanitation & & $\begin{array}{c}-0.0169 * * * \\
(0.0055)\end{array}$ & & $\begin{array}{c}-0.0100^{* *} \\
(0.0039)\end{array}$ \\
\hline Improved Water & & $\begin{array}{c}-0.0137 * * * \\
(0.0037)\end{array}$ & & $\begin{array}{c}-0.0071^{* * *} \\
(0.0027)\end{array}$ \\
\hline Observations & 169,264 & 169,264 & 274,712 & 274,712 \\
\hline R-squared & 0.1376 & 0.1380 & 0.1572 & 0.1576 \\
\hline
\end{tabular}

Notes: The dependent variable is an indicator variable which takes the value one if the respondent was sexually active in the four weeks preceding the interview. "Demeaned Temperature at Interview - X" refers to the demeaned temperature in Celsius degrees prevailing in the respondent's region X months before the interview. Standard errors, clustered at the region level, are in parentheses. ${ }^{* * *} \mathrm{p}<0.01,{ }^{* *}$ $\mathrm{p}<0.05,{ }^{*} \mathrm{p}<0.1$.

\section{Appendix D: Non-linear Temperature Effects}

Table D1: Non-linear Effects of Temperature at Conception on Outcomes - Polynomials in Levels

\begin{tabular}{lccc}
\hline & $\begin{array}{c}(1) \\
\text { Years of Schooling }\end{array}$ & $\begin{array}{c}(2) \\
\text { Literacy }\end{array}$ & $\begin{array}{c}(3) \\
\text { No Disability }\end{array}$ \\
\hline Temperature at Birth - 9 & $-6.96^{* * *}$ & -0.262 & 0.0124 \\
& $(2.23)$ & $(0.222)$ & $(0.0355)$ \\
$(\text { Temperature at Birth - } 9)^{2}$ & $0.462^{* * *}$ & 0.0179 & -0.000902 \\
& $(0.149)$ & $(0.0148)$ & $(0.00221)$ \\
$(\text { Temperature at Birth - } 9)^{3}$ & $-0.0135^{* * *}$ & -0.000529 & $2.79 \mathrm{e}-05$ \\
& $(0.00436)$ & $(0.000436)$ & $(6.05 \mathrm{e}-05)$ \\
$(\text { Temperature at Birth - } 9)^{4}$ & $0.000147^{* * *}$ & $5.76 \mathrm{e}-06$ & $-3.16 \mathrm{e}-07$ \\
& $(4.71 \mathrm{e}-05)$ & $(4.75 \mathrm{e}-06)$ & $(6.12 \mathrm{e}-07)$ \\
Precipitation at Birth - 9 & $5.74 \mathrm{e}-05$ & $8.06 \mathrm{e}-06$ & $-3.71 \mathrm{e}-06$ \\
& $(0.000159)$ & $(1.37 \mathrm{e}-05)$ & $(2.42 \mathrm{e}-06)$ \\
& & & \\
Country-Year of Birth FE & Yes & Yes & Yes \\
Region-Month of Birth FE & Yes & Yes & Yes \\
Precipitation at Birth - 9 & Yes & Yes & Yes \\
Observations & $3,475,680$ & $3,475,680$ & $3,475,680$ \\
R-squared & 0.256 & 0.174 & 0.014 \\
\hline
\end{tabular}

Notes: The variable "Temperature at Birth - X" refers to the temperature in Celsius degrees which prevails $\mathrm{X}$ months before birth. All regressions cluster at the region level. All regressions contain country-year fixed effects and region-month fixed effects. Standard errors are in parentheses. ${ }^{* * *} \mathrm{p}<0.01,{ }^{* *} \mathrm{p}<0.05$, ${ }^{*} \mathrm{p}<0.1$. 
Table D2: Non-linear Effects of Temperature at Conception on Outcomes - Polynomials in Standard Deviations

\begin{tabular}{lccc}
\hline & $\begin{array}{c}(1) \\
\text { Years of Schooling }\end{array}$ & $\begin{array}{c}(2) \\
\text { Literacy }\end{array}$ & $\begin{array}{c}(3) \\
\text { No Disability }\end{array}$ \\
\hline Temperature Deviation at Birth - 9 & $0.0145^{* *}$ & $0.00182^{* * *}$ & -0.000231 \\
& $(0.00652)$ & $(0.00632)$ & $(0.000148)$ \\
$(\text { Temperature Deviation at Birth }-9)^{2}$ & -0.00429 & 0.000203 & $-1.09 \mathrm{e}-05$ \\
& $(0.00362)$ & $(0.000299)$ & $(7.07 \mathrm{e}-05)$ \\
$(\text { Temperature Deviation at Birth - } 9)^{3}$ & $0.00380^{* *}$ & $9.42 \mathrm{e}-05$ & $3.83 \mathrm{e}-05$ \\
& $(0.00189)$ & $(0.000196)$ & $(3.40 \mathrm{e}-05)$ \\
Precipitation at Birth - 9 & $7.01 \mathrm{e}-05$ & $8.04 \mathrm{e}-06$ & $-3.77 \mathrm{e}-06$ \\
& $(0.000159)$ & $(1.36 \mathrm{e}-05)$ & $(2.42 \mathrm{e}-06)$ \\
Observations & & & \\
R-squared & $3,475,680$ & $3,475,680$ & $3,475,680$ \\
\hline
\end{tabular}

Notes: The variable "Temperature Deviation at Birth - X" refers to the temperature deviation from the average temperature for a region-year in Celsius degrees which prevails X months before birth measured in standard deviations. All regressions cluster at the region level. All regressions contain country-year fixed effects and region-month fixed effects. Standard errors are in parentheses. ${ }^{* * *} \mathrm{p}<0.01,{ }^{* *} \mathrm{p}<0.05$, ${ }^{*} \mathrm{p}<0.1$.

Table D3: Non-linear Effects of Temperature at Conception on Years of Schooling Standardized Shocks

\begin{tabular}{|c|c|c|c|c|}
\hline & $\begin{array}{c}(1) \\
\text { Years of } \\
\text { Schooling }\end{array}$ & $\begin{array}{c}(2) \\
\text { Years of } \\
\text { Schooling }\end{array}$ & $\begin{array}{c}(3) \\
\text { Years of } \\
\text { Schooling }\end{array}$ & $\begin{array}{c}(4) \\
\text { Years of } \\
\text { Schooling }\end{array}$ \\
\hline & & & & \\
\hline$+/$ - One s.d. Shock at Birth - 9 & $\begin{array}{l}-0.00848 \\
(0.0113)\end{array}$ & & & \\
\hline One s.d. Cooler Shock at Birth - 9 & & $\begin{array}{c}-0.0446^{* * *} \\
(0.0162)\end{array}$ & & \\
\hline One s.d. Warmer Shock at Birth - 9 & & $\begin{array}{c}0.0257 \\
(0.0195)\end{array}$ & & \\
\hline$+/-$ Two s.d. Shock at Birth - 9 & & & $\begin{array}{c}0.0265 \\
(0.0226)\end{array}$ & \\
\hline Two s.d. Cooler Shock at Birth - 9 & & & & $\begin{array}{l}-0.0261 \\
(0.0404)\end{array}$ \\
\hline Two s.d. Warmer Shock at Birth - 9 & & & & $\begin{array}{c}0.0484 \\
(0.0329)\end{array}$ \\
\hline Precipitation at Birth - 9 & $\begin{array}{l}1.10 \mathrm{e}-05 \\
(0.000157)\end{array}$ & $\begin{array}{c}5.68 \mathrm{e}-05 \\
(0.000161)\end{array}$ & $\begin{array}{c}1.13 \mathrm{e}-05 \\
(0.000157)\end{array}$ & $\begin{array}{c}1.71 \mathrm{e}-05 \\
(0.000157)\end{array}$ \\
\hline Observations & $3,475,680$ & $3,475,680$ & $3,475,680$ & $3,475,680$ \\
\hline R-squared & 0.256 & 0.256 & 0.256 & 0.256 \\
\hline
\end{tabular}

Notes: The variable "Shock at Birth - X" is an indicator variable for whether the temperature deviation at $\mathrm{X}$ months before birth is larger than the number of standard deviations indicated in the variable name from the region-month average. "Cooler Shock" and "Warmer Shock" are the same as "Shock", except that the indicator only takes the value of 1 if the temperature deviation is larger than the indicated number of standard deviations warmer or cooler from the region-month average respectively. All regressions cluster at the region level. All regressions contain country-year fixed effects and region-month fixed effects. Standard errors are in parentheses. ${ }^{* * *} \mathrm{p}<0.01,{ }^{* *} \mathrm{p}<0.05,{ }^{*} \mathrm{p}<0.1$. 
Table D4: Non-linear Effects of Temperature at Conception on Literacy - Standardized Shocks

\begin{tabular}{|c|c|c|c|c|}
\hline & $\begin{array}{c}(1) \\
\text { Literate }\end{array}$ & $\begin{array}{c}(2) \\
\text { Literate } \\
\end{array}$ & $\begin{array}{c}(3) \\
\text { Literate }\end{array}$ & $\begin{array}{c}(4) \\
\text { Literate }\end{array}$ \\
\hline +/- One s.d. Shock at Birth - 9 & $\begin{array}{c}0.00116 \\
(0.00104)\end{array}$ & & & \\
\hline One s.d. Cooler Shock at Birth - 9 & & $\begin{array}{l}-0.00128 \\
(0.00125)\end{array}$ & & \\
\hline One s.d. Warmer Shock at Birth - 9 & & $\begin{array}{c}0.00346^{* *} \\
(0.00164)\end{array}$ & & \\
\hline +/- Two s.d. Shock at Birth - 9 & & & $\begin{array}{c}0.00257 \\
(0.00189)\end{array}$ & \\
\hline Two s.d. Cooler Shock at Birth - 9 & & & & $\begin{array}{l}-0.00383 \\
(0.00247)\end{array}$ \\
\hline Two s.d. Warmer Shock at Birth - 9 & & & & $\begin{array}{l}0.00523^{*} \\
(0.00275)\end{array}$ \\
\hline Precipitation at Birth - 9 & $\begin{array}{c}2.77 \mathrm{e}-06 \\
(1.34 \mathrm{e}-05)\end{array}$ & $\begin{array}{c}5.86 \mathrm{e}-06 \\
(1.39 \mathrm{e}-05)\end{array}$ & $\begin{array}{c}2.88 \mathrm{e}-06 \\
(1.34 \mathrm{e}-05)\end{array}$ & $\begin{array}{c}3.60 \mathrm{e}-06 \\
(1.35 \mathrm{e}-05)\end{array}$ \\
\hline Observations & $3,475,680$ & $3,475,680$ & $3,475,680$ & $3,475,680$ \\
\hline R-squared & 0.174 & 0.174 & 0.174 & 0.174 \\
\hline
\end{tabular}

Notes: The variable "Shock at Birth - X" is an indicator variable for whether the temperature deviation at $\mathrm{X}$ months before birth is larger than the number of standard deviations indicated in the variable name from the region-month average. "Cooler Shock" and "Warmer Shock" are the same as "Shock", except that the indicator only takes the value of 1 if the temperature deviation is larger than the indicated number of standard deviations warmer or cooler from the region-month average respectively. All regressions cluster at the region level. All regressions contain country-year fixed effects and region-month fixed effects. Standard errors are in parentheses. ${ }^{* * *} \mathrm{p}<0.01,{ }^{* *} \mathrm{p}<0.05,{ }^{*} \mathrm{p}<0.1$. 
Table D5: Non-linear Effects of Temperature at Conception on Disability - Standardized Shocks

\begin{tabular}{|c|c|c|c|c|}
\hline & $\begin{array}{c}(1) \\
\text { Disabled }\end{array}$ & $\begin{array}{c}(2) \\
\text { Disabled }\end{array}$ & $\begin{array}{c}(3) \\
\text { Disabled }\end{array}$ & $\begin{array}{c}(4) \\
\text { Disabled }\end{array}$ \\
\hline +/- One s.d. Shock at Birth - 9 & $\begin{array}{l}-0.000104 \\
(0.000226)\end{array}$ & & & \\
\hline One s.d. Cooler Shock at Birth - 9 & & $\begin{array}{c}3.02 \mathrm{e}-05 \\
(0.000315)\end{array}$ & & \\
\hline One s.d. Warmer Shock at Birth - 9 & & $\begin{array}{l}-0.000231 \\
(0.000297)\end{array}$ & & \\
\hline +/- Two s.d. Shock at Birth - 9 & & & $\begin{array}{l}-0.000265 \\
(0.000414)\end{array}$ & \\
\hline Two s.d. Cooler Shock at Birth - 9 & & & & $\begin{array}{l}-0.000205 \\
(0.000790)\end{array}$ \\
\hline Two s.d. Warmer Shock at Birth - 9 & & & & $\begin{array}{l}-0.000290 \\
(0.000477)\end{array}$ \\
\hline Precipitation at Birth - 9 & $\begin{array}{l}-3.40 \mathrm{e}-06 \\
(2.41 \mathrm{e}-06)\end{array}$ & $\begin{array}{l}-3.57 \mathrm{e}-06 \\
(2.41 \mathrm{e}-06)\end{array}$ & $\begin{array}{l}-3.41 \mathrm{e}-06 \\
(2.42 \mathrm{e}-06)\end{array}$ & $\begin{array}{l}-3.42 \mathrm{e}-06 \\
(2.41 \mathrm{e}-06)\end{array}$ \\
\hline Observations & $3,475,680$ & $3,475,680$ & $3,475,680$ & $3,475,680$ \\
\hline R-squared & 0.014 & 0.014 & 0.014 & 0.014 \\
\hline
\end{tabular}

Notes: The variable "Shock at Birth - X" is an indicator variable for whether the temperature deviation at $\mathrm{X}$ months before birth is larger than the number of standard deviations indicated in the variable name from the region-month average. "Cooler Shock" and "Warmer Shock" are the same as "Shock", except that the indicator only takes the value of 1 if the temperature deviation is larger than the indicated number of standard deviations warmer or cooler from the region-month average respectively. All regressions cluster at the region level. All regressions contain country-year fixed effects and region-month fixed effects. Standard errors are in parentheses. ${ }^{* * *} \mathrm{p}<0.01,{ }^{* *} \mathrm{p}<0.05,{ }^{*} \mathrm{p}<0.1$. 
Figure D1: The Effect of Temperature 9 Months before Birth on Outcomes by Average Region Temperature
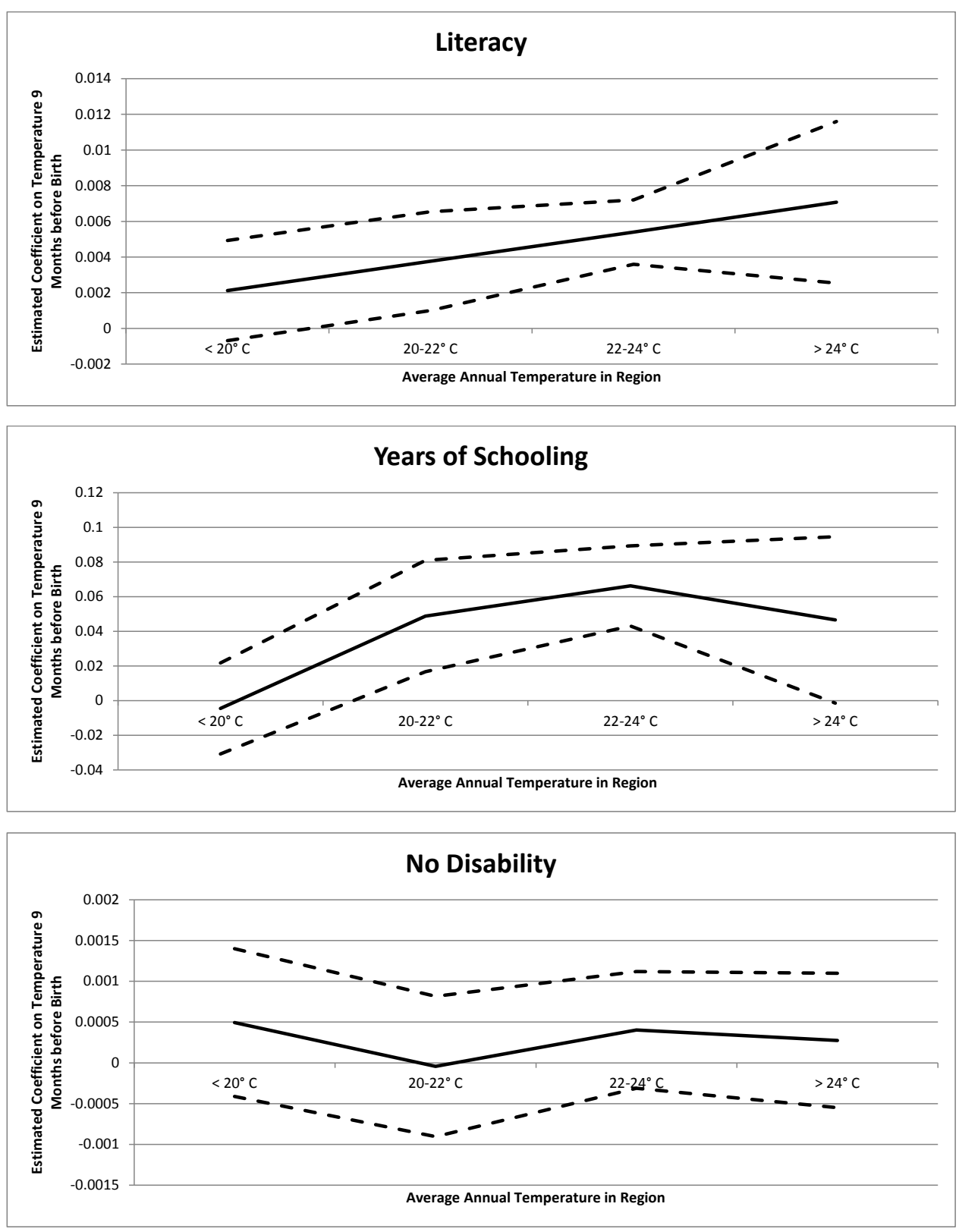
Figure D2: The Effect of Temperature 9 Months before Birth on Outcomes - Non-linear Polynomial Effects in Levels

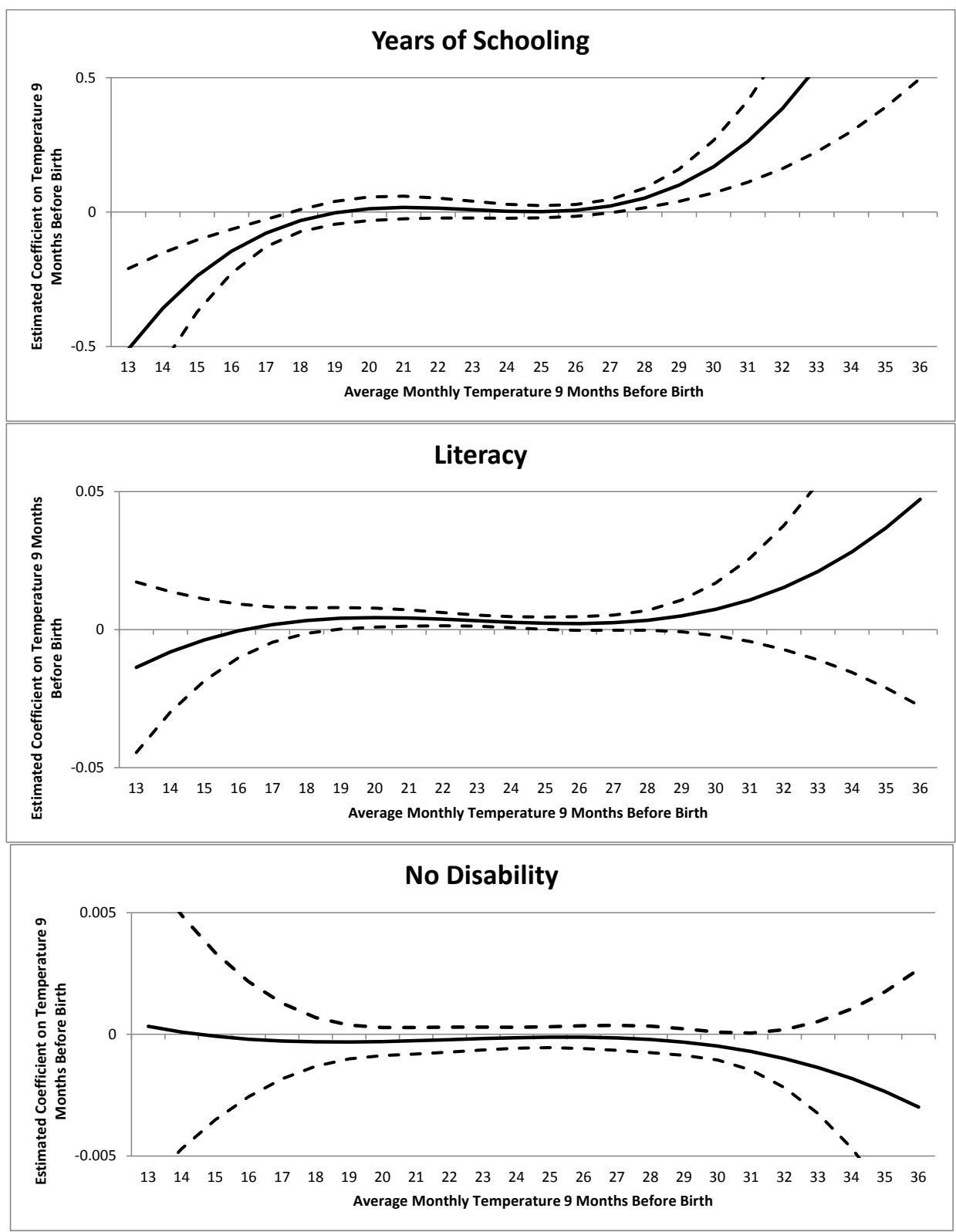




\section{Appendix E: Figures}

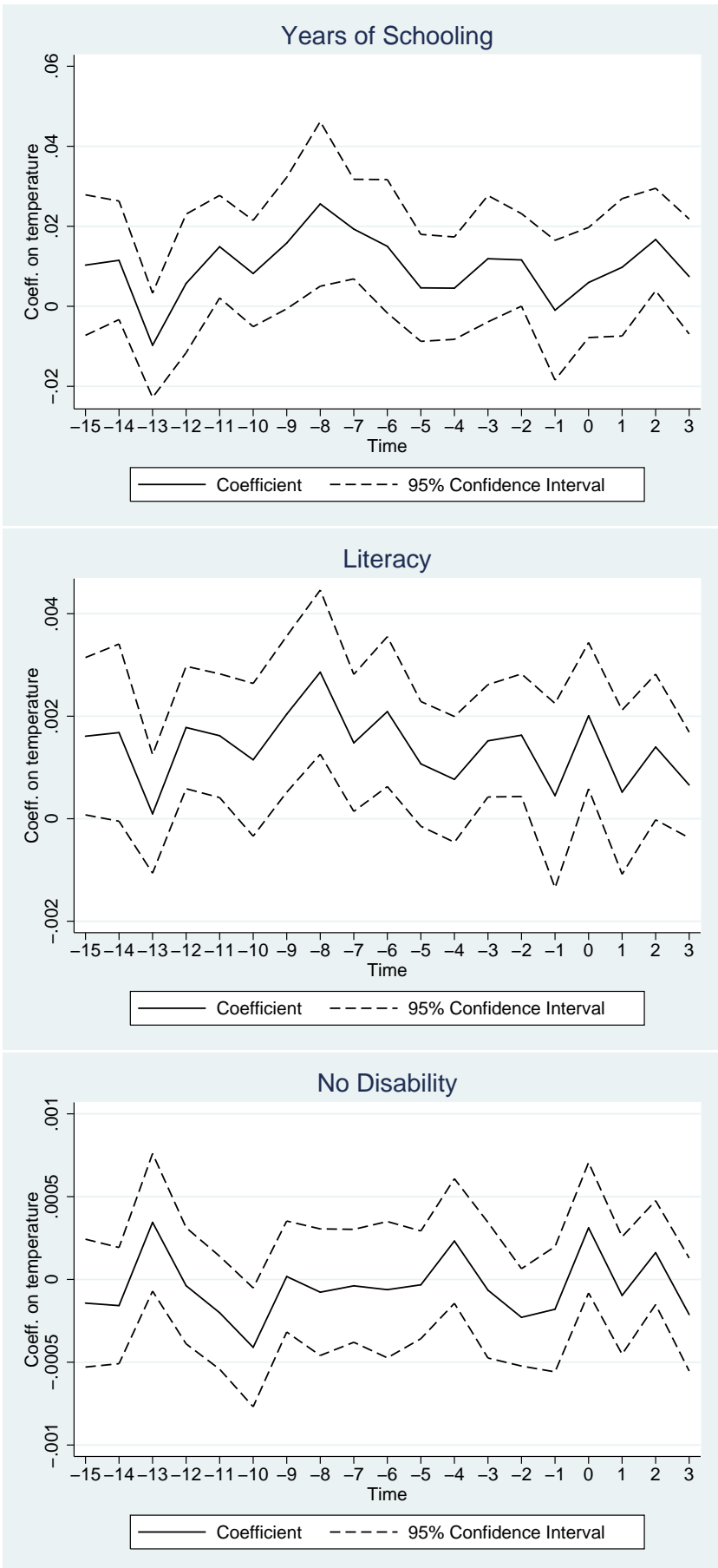

